\title{
HOMBRES DE NEGOCIOS \\ Y FINANZAS PÚBLICAS \\ EN LA CATALUÑA DE FELIPE II *
}

BERNARDO HERNÁNDEZ

Universidad Autónoma de Barcelona

\section{RESUMEN}

Se aborda la necesidad de investigar las conexiones entre capital privado y público en la articulación y funcionamiento de la Hacienda Real en la Cataluña de mediados del siglo XVI. Se pone de manifiesto la existencia de un poderoso sector privado de hombres de negocios que entra en contacto con los administradores hacendísticos para hacer frente a las necesidades monetarias de la Monarquía. El artículo analiza la frecuencia de contratos de crédito, negociados a través de letras de cambio libradas sobre las ferias de Lyon, y los mecanismos especulativos asociados que permiten apreciar el alto componente financiero y mercantil efectivo de la fiscalidad real en Cataluña.

\section{ABSTRACT}

The autor deals with the need for researches based on the connection of private and public capital in the functioning of the royal finances in Catalonia of the 16th-century. B. Hernandez describes the existence of a powerful private sector of business-men that contacted with the fiscal administrators in order to face the monetary necessities of the Monarchy. This article analyzes the frequency of credit contracts negociated though bills of exchange dispatched on the fairs of Lyons and the associated speculative mechanisms that allow to evaluate the importance of fiscal and mercantile factors thats had intervened in the royal financial system in Catalonia.

* El autor agradece las sugerencias y críticas efectuadas por los evaluadores anónimos de la Revista de Historia Económica al artículo original. Especialmente, reconoce la depuración terminológica que ha llevado a cabo a partir de las consideraciones que se le han hecho llegar. La versión que se publica intenta reflejar esas puntualizaciones; por supuesto, la responsabilidad final de los detalles discutibles es estrictamente de B. Hernández. 


\section{INTRODUCCIÓN}

Pese a la atención mostrada por el desarrollo fiscal del estado moderno en la Corona de Castilla, lo que conocemos sobre la hacienda periférica de la Monarquia en Cataluña es muy poco. El desinterés historiográfico por evaluar y estudiar con profundidad el desarrollo de un aparato fiscal propio de la Corona vino motivado por el resultado de las primeras prospecciones en torno al tema que mostraron las dificultades documentales, la escasez de ingresos fiscales del rey en Cataluña y el amplio margen de autonomía financiera de que gozaba la Diputación del General '. Respecto a la inclusión de Cataluña en un análisis de la hacienda imperial, ha persistido la visión de una mínima integración entre el aparato fiscal castellano y el mundo de las finanzas catalanas durante el reinado de Felipe II que haría poco viable el análisis desde perspectivas estatalistas del ámbito fiscal de la Corona de Aragón ${ }^{2}$. En cualquier caso, una investigación que implique aspectos centrales y periféricos de la hacienda y la fiscalidad de la Monarquía en Cataluña queda por hacer.

Sin embargo, el trabajo sobre esta temática se impone por las originales respuestas que la propia Monarquía dio a su situación de penuria monetaria. En la Cataluña del siglo Xvi, el sistema hacendístico real se encontraba limitado por dos importantes circunstancias: unas fuentes de ingresos en el Principado inadecuadas para el sostenimiento de las necesidades monetarias producidas por los gastos bélicos (las fronteras, terrestre con Francia y mediterránea con el corsarismo norteafricano) y un estructural déficit financiero en la administración virreinal, consecuencia del imposible envio regular de remesas monetarias suficientes desde la Corona de Castilla ${ }^{3}$. Aunque esta situación era similar a la de otros territorios de la Monarquía Católica, en Cataluña tuvo unos rasgos más acusados. No sólo por la persistencia de una situación constitucional muy sólida que hizo fracasar los ensayos de implantación fiscal y renovación de las rentas patrimoniales - esto es, aquellas pertenecientes al monarca como incorporadas a su patrimonio personal - emprendidos repetidamente desde mediados del siglo XvI ${ }^{4}$, sino por la propia situación geopolítica en el

1 Elliott (1989), pp. 85-90.

2 Bernabé (1993), p. 15.

${ }^{3}$ La estructura, organización y funcionamiento de la Real Hacienda en Cataluña, así como su evolución global entre 1516 y 1640, organizada en torno a las tres oficinas contables del Baile General, Regente la Tesorería-Tesorero General de la Corona y Pagador, ha sido esbozada por Hernández (1995), pp. 50-238. Los planteamientos concretos del desarrollo del aparato fiscal de la Real Hacienda y de la Generalitat, en la segunda mitad del siglo XVI, son el objeto de la tesis doctoral del autor.

4 Hernández (1993), pp. 31-33. 
núcleo de las rutas de funcionamiento y flujo dinerario del Imperio en la segunda mitad del siglo Xvi. Eso favoreció el surgimiento, en algunos casos, la reorientación, en otros, de una gran parte del mundo mercantil y negociante catalán interesado en el campo del beneficio que representaban los frecuentes gastos públicos de abastecimiento e infraestructura realizados por el pagador del ejército y fronteras o la labor de intermediación en los tratos del capitalismo internacional. En este sentido, Cataluña se inserta en el marco de la república internacional del dinero; se convierte en una zona financiera en la que el metal precioso controlado por el capitalismo italiano, sin detenerse en su su tránsito de Sevilla-Castilla a Italia-Flandes provoca efectos positivos sobre el tejido mercantil autóctono, aunque sometido al papel de factor del predominio económico genovés '.

Actualmente las orientaciones de la historia financiera ayudan a perfilar con mayor detalle las posibles aproximaciones a la fiscalidad real en Cataluña y permiten valorar equilibradamente los distintos componentes de la situación. Por una parte es plenamente aceptada la imposibilidad de abordar desde un punto de vista exclusivamente institucional (órganos de administración y tipología impositiva) los aspectos hacendísticos del Antiguo Régimen. Procedimientos crediticios, administración por arriendo de ingresos fiscales, asientos o cambios son sólo algunos ejemplos de la existencia de territorios de actuación con gran confusión entre lo público y lo privado. La estructura hacendística descansa sobre la existencia ambivalente de una red de crédito relacionado con el capital financiero privado y un conglomerado de instrumentos de recaudación fiscal directa e indirecta, literalmente volcados en hacer frente a las necesidades de la administración ${ }^{6}$. Se insiste, además, en la presencia en las operaciones contables de los hombres de negocios, que proporcionan crédito para los ingresos de la cuenta de los oficiales reales y que se benefician de los gastos efectuados por éstos en compras de mercancías o reembolso de cambios.

Por otro lado, aunque todavía mal conocida, es indudable la potencia de los sectores comerciales y financieros catalanes durante el reinado de Felipe II. Frente a la idea de decadencia aplicada a Barcelona y la Cataluña del Quinientos, los estudios de P. Vilar mostraron lo variable de la coyuntura a lo largo del siglo XVI y relativizaron la pertinencia de cualquier juicio genérico. Recientes investigaciones no han hecho más que refrendar lo establecido por el historiador francés, aunque sigan mostrando una excesiva prudencia a la hora de valorar eficazmente las oportunidades representadas para el capital privado por la ex-

5 Hernández (1995b).

6 Dedieu/Ruiz (1994), pp. 79-81. 
tensión del gasto de la Monarquía desde mediados del siglo xvI o continúen insistiendo en la ausencia de una gran finanza en la Barcelona de la época 7.

Por tanto, este articulo aporta unas primeras valoraciones sobre un campo de estudio abierto. Un panorama muy general que deberá ser completado con múltiples detalles, toda vez que conocida la faceta de las finanzas de la Corona se integren luego las conclusiones -en un estudio comparativo- en el conjunto de la realidad fiscal representada, también, por la Diputación en el Principado. Aqui, tal y como lo he presentado, abordo tan sólo un aspecto descriptivo de los mecanismos de financiación del gasto de la Monarquía hispánica en la Cataluña del reinado de Felipe II. Expongo cómo se interrelacionaron los ámbitos de actuación del capital privado catalán (representados por importantes hombres de negocios barceloneses) y las necesidades monetarias inexcusables de los pagadores de los ejércitos y galeras reales, en la segunda mitad del siglo XVI, mediante un complejo sistema de letras de cambio giradas desde Barcelona sobre las ferias lyonesas. Estas letras permitieron el establecimiento de acuerdos de crédito que hicieron posible - en determinadas coyunturassostener económicamente los gastos estratégicos de la Monarquía en Cataluña.

De lo que se trata, en un plan de exposición, es de señalar los rasgos generales de los hombres de negocios en la Cataluña de Felipe II y situar su interrelación con los mecanismos de funcionamiento efectivo o cotidiano de las estructuras hacendísticas coetáneas. En este sentido, ha parecido oportuno introducir un estudio detenido de uno de los diversos procedimientos crediticios de la Monarquía en Cataluña, que muestra perfectamente la integración de los métodos especulativos privados en el ámbito operativo y contable del pagador, el principal oficial financiero de la administración real en Cataluña, encargado fundamentalmente de administrar el dinero enviado por la Hacienda Real para mantener presidios, fortalezas y galeras.

\section{LOS HOMBRES DE NEGOCIOS CATALANES EN LA SEGUNDA MITAD DEL SIGLO XVI}

Los fundamentos de la situación comercial catalana del siglo XVI pueden verse tempranamente en las referencias a la presencia de mercaderes en las ferias castellanas recogidas en la obra de P. Vilar, que siguió las investigaciones de Carrera Pujal ${ }^{8}$. En cualquier caso, lo que interesa destacar de estas relacio-

7 Torres (1992), pp. 222-224; Vázquez de Prada (1993), p. 499.

* Vilar (1968), p. 242 y ss. 
nes financiero-mercantiles es que existieron desde finales del siglo $\mathrm{XV}$ de una manera muy dinámica, al margen de los planteamientos de carácter económico más global que se defendieron en Cortes o por la ciudad de Barcelona en sus representaciones ante los monarcas. Lo más característico, sin embargo, no es tanto insistir sobre la magnitud de estos contactos internacionales como plantear las características de su desarrollo posterior. Un desarrollo que no consistió en la profundización exclusiva de las relaciones con la $\mathrm{Co}$ rona de Castilla o los restantes reinos de la Corona de Aragón. En este sentido, la falta de datos sobre un apogeo - conceptuado como necesario- del comercio y de la economía en un binomio Cataluña-Castilla ha llevado a concluir el presunto retraimiento que experimentaron los circuitos financieros catalanes en el siglo Xvi. Y a tender, en la analogía, a situar en la debilidad económica una de las razones fundamentales que explican la escasa intervención catalana o la imposibilidad de participar en los mecanismos de las finanzas imperiales.

Lo que se aprecia es, si no lo contrario, sí un espacio geográfico peculiar de desarrollo en las relaciones comerciales catalanas. Barcelona y su capital mercantil habían orientado desde antes del siglo xv su política comercial y económica a la relación mediterránea con Italia. Interesados en participar en las redes del capitalismo europeo que crece a lo largo del siglo XVI, esta vinculación mediterránea favoreció simultáneamente tempranos intereses en la ciudad francesa de Lyon. Una conexión tanto más incrementada cuanto, a medida que transcurre el siglo, las plazas de cambios peninsulares presenten sintomas de agotamiento. Son, concretamente, estos contactos con el marco de las ferias francesas los que proporcionan una de las bases del estudio.

En esta linea, unas breves referencias a tres familias de hombres de negocios catalanes logran exponer sumariamente el ámbito internacional de negocios del capital catalán a mediados del siglo Xvi, la riqueza de sus relaciones y la implicación selectiva en las redes de crédito de la hacienda de Felipe II. Los Granollachs, los Puiggener y los Sauri se erigen en representantes de lo complejo de un panorama que sólo ahora, exceptuando algunas investigaciones pioneras de F. Ruiz Martin, comienza a ser conocido.

Joan Granollachs está establecido en Lyon, al menos desde 1571, cuando Gascon lo señala como situado «au niveau des marchands lyonnais aisés, non des plus riches». Es en 1576, sin embargo, cuando ya es considerado un acreditado exportador de paños franceses hacia España. En Lyon, los distintos miembros de la familia establecen relaciones muy estrechas con los Bonvisi (banqueros que desarrollan en esta época un comercio de alumbre y azafrán 
centrado en el ámbito catalán); los Granollachs se constituirían en factores de estos italianos en los negocios con el Levante peninsular ${ }^{9}$.

Entre 1574 y 1585, Miquel Granollachs participó en negocios cambiarios en Valencia, representando a la firma Bernardi, Francesc \& Joan Granollachs. Desde 1585, los catalanes abren una agencia en Madrid, con negociaciones en las ferias castellanas y gestionada por Guillem Ramon Granollachs. Paulatinamente, la red financiera de esta importante familia catalana se extiende asombrosamente; mediante licencias de propio uso reales, los hermanos Bernardí y Francesc Granollachs sacaron de Cataluña hacia las ferias de Besançon y hacia Francfort más de 2.740 .000 sueldos (el sueldo barcelonés equivale a $1 / 2$ real castellano) en el primer semestre de $1587^{10}$. Extensión geográfica y de jerarquización económica también, como se pone de manifiesto - siempre según la correspondencia de Simón Ruiz- con la participación en un asiento mancomunado por intermedio de los Balbani de Lyon en 1579 ".

Junto con los Granollachs, la familia Puiggener destacó desde mediados del siglo XVI en la participación activa de las finanzas catalanas sobre el sistema financiero y fiscal de la Monarquía. Los Puiggener son el ejemplo más perfecto de una evolución secular desde el campesinado acomodado a la nobleza. En este proceso, los negocios no fueron algo ajeno ${ }^{12}$. Ya los primeros datos sobre esta familia se obtienen de las licencias de saca negociadas en el Consejo de Hacienda a favor de Pau Puiggener en 1564. La familia barcelonesa poseía un banco privado en Barcelona. En las décadas siguientes Pau y Miquel Puiggener gestionan diversas sucursales en Madrid y Valencia con los Camarena, con representaciones en las ferias de Medina del Campo. Entre 1584 y 1586, son activos intermediarios en los libros de cuentas de la tesorería general de la Corona de Aragón. Los negocios van en aumento y, en el año 1589, una carta de Felipe Jorge desde Amberes a Simón Ruiz pone de manifiesto el amplísimo campo de relaciones de los catalanes Puiggener: mantenian negocios simultáneos en Madrid, Valencia, Lyon y Medina del Campo. Situación que les permite, además, participar en asientos desde 1587.

9 Gascon (1971), vol. I, pp. $96-98$ y 322, y vol. II, pp. 360 y 657. AHBC (Archivo Histórico de la Biblioteca de Cataluña), not. Miquel Axada, Secundum manuale contractuum communium 1585 1586, escritura de fecha 1586-03-31.

${ }^{10}$ Más datos económicos de los Granollachs pueden verse en Hernández (1995), pp. 333 . 336; remito a ese estudio, en general, para evitar un excesivo número de notas documentales que hagan referencia a detalles.

"AHPUV (Archivo Histórico Provincial y Universitario de Valladolid), SR (Fondo Simón Ruiz), 54/16 (citado, en adelante, por el número de caja y el número de carta); Beneditto y Bernardo Balbani a Simón Ruiz (Lyon, 1579-02-02).

12 Hernández (1995), pp. 336-340; Fluvià (1994). 
Entre 1585 y 1588, Miquel Puiggener y otros familiares fueron tesoreros de la Santa Cruzada en el Principado. En 1586, Miquel Puiggener, representado por su padre Damià, rehusó pagar 1.000 .000 de maravedís en Barcelona. Su asiento de administración respondia al arca central del Consejo de Cruzada en Madrid. Un intento de hacerle desembolsar el numerario en la misma Barcelona, sin embargo, provocó que los Puiggener protestaran vivamente («dixo que protestava por el danyo que le dan en pagar en la presente ciudad en la tabla della por tener dineros en la villa de Madrit para el dicho effecto»). En la disputa se percibe un intento por parte de la Real Hacienda de situar en Barcelona un dinero preciso, evitando el giro de letras de cambios o cédulas de pago. La actitud de los Puiggener en este caso muestra claramente el interés común de los mercaderes por mantener liquidez en Madrid, por una parte, a la vez que la falta de moneda metálica en Cataluña seguía encareciendo los créditos que debiera contratar el pagador para hacer frente a las deudas; situación que, por otro lado, beneficiaba a los mismos negociantes que querían tipos de interés elevados ${ }^{13}$. En 1589, Pau y Miquel Puiggener, junto con Francesc de Rovirola, Jaume Ferrer y Jaume Llebre, formaron una compañia en Lyon. Ello favoreció e incrementó el encuentro y los contactos entre los mercaderes y los agentes de la Corona en Cataluña en la forma que más adelante veremos.

Sin embargo, los límites de la implicación financiera más allá del ámbito estrictamente catalán - tema que podrá ser abordado detenidamente en otra ocasión - también pueden establecerse destacando el escaso interés mostrado por los Puiggener en torno al sistema de la deuda pública castellana. Son contadas en los registros de la Contaduria de Mercedes las referencias a la posesión de juros por las grandes fortunas catalanas de la época. Entre ellas, la adquisición por los Puiggener a Juan de Izaguirre de un juro de 13.038 maravedís de renta situado sobre el Almojarifazgo de Sevilla. El juro, cobrado por Miquel Puiggener entre 1586 y 1601, presentó problemas de pago posteriormente. Esto obligó a que en 1608 se solicitara ante el Consejo de Hacienda una actualización de los derechos de cobro. En 1609, a la muerte de su esposa (Margarida Lucià), Puiggener endosó el juro a su suegro como devolución de la dote; éste continuó los trámites hasta que en 1614 se expidió un nuevo justificante del juro originalmente creado en $1502^{14}$. ¿Es posible deducir, por tanto, un conservadurismo del capital catalán a la hora de actuar fuera de un espacio relativamente autoprotegido como Cataluña? La impresión del desinterés por intervenir en el siste-

\footnotetext{
13 AGS (Archivo General de Simancas), Comisaria de Cruzada, leg. 326; Archivo Diocesano de Barcelona, Santa Cruzada, vol. 21, f. 534.535v (1586-04-03).

14 AGS, Contaduria de Mercedes, leg. 75, f. 6.
} 
ma fiscal castellano así lo demostraria. Aunque la trayectoria de los Sauri ofrece algunos detalles en contra de esta hipótesis, todavía sin contrastar efectivamente en su totalidad, es importante también considerar el carácter no especulativo de los juros, como instrumentos financieros que procedian mayoritariamente del reembolso de créditos obligados con la Real Hacienda ${ }^{15}$.

Por fin, respecto a los Sauri - sobre quienes Ruiz Martín llamó la atención hace más de veinte años- hay que considerarlos, por el momento, los más destacados financieros catalanes del siglo XVI ${ }^{16}$. Desde 1542 negocian cambios en las ferias castellanas y actúan como comisionados de Barcelona ante la corte. Son elementos clave en el inicio del proceso de recaudación del Excusado en Cataluña, lo que les comportará numerosos problemas a la vez que múltiples tratos directos con el Consejo de Hacienda. De estas relaciones surgirá la participación en asientos de abastecimiento a las galeras mediterráneas. Afectados de pleno por la suspensión de pagos de 1575 , irian cobrando sus deudas a partir de los servicios del Principado a la Corona en las Cortes de 1585.

Todos estos datos, susceptibles de ser ampliados a través de un estudio exhaustivo de los protocolos barceloneses, muestran que la estela de los Sauri descrita por Ruiz Martín no fue única. Solamente una investigación metódica a partir de los archivos notariales permitirá precisar el alcance efectivo de esta integración de los financieros catalanes en el marco del día a día de ingresos y gastos de la Monarquía en Cataluña.

Las breves referencias, sin embargo, logran establecer una serie de caracteres específicos que ayudan a hacer coherente la presentación de un marco financiero privado muy activo (a nivel nacional e internacional) en la Cataluña de la segunda mitad del siglo xvi. Establecidas las bases fundacionales de unas fortunas con una gama de operaciones muy diversa, quedan abiertas futuras lineas de investigación que maticen los frutos concretos de estas capacidades de intervención indiscutible y discutan su cronologia. En el artículo nos limitamos a presentar esta actuación en el espacio catalán, destacando los puntos más interesantes de contacto.

\section{LAS FINANZAS DE LA MONARQUIA EN CATALUÑA Y LA INTERVENCION DEL CAPITAL PRIVADO}

Ruiz Martín señaló que, a grandes rasgos, hasta 1570 primó la demanda privada de bienes de consumo en el conjunto de los territorios peninsulares,

is Es el caso de los juros anulados de los Sauri o del mismo Puiggener. Véase AGS, VariosJuros rasgados, legs. 55 (f. 27), 56 (f. 70), 74 (f. 70 ) y 91 (f. 92).

16 Ruiz Martin (1975), p. 476; Hernández (1995), pp. 340-342. 
pero que la proporción se invertía desde esa fecha ${ }^{17}$. La consideración la hacía globalmente, pues para Cataluña la duración y tendencia de este desarrollo de la demanda pública se puede afinar. Pero es constante una idea; la de la Monarquía como el principal empresario del siglo XVI, en palabras de Braudel ${ }^{18}$. Dentro de esta categoría de «operaciones públicas», lo que interesa es la consideración de este concepto en relación con la manera como se solventaron las necesidades de los agentes reales mediante los contactos que establecieron con la red comercial barcelonesa.

Una vez expuestos algunos rasgos de los mercaderes catalanes de la época, intento plantear los principales campos de encuentro entre el gasto público y los hombres de negocios, en general, durante la segunda mitad del siglo XVI. Utilizando el diseño de lo que la historiografía francesa ha denominado estado de finanzas; esto es, otorgando en un análisis de historia global una gran trascendencia al sistema fiscofinanciero que permitiria el correcto funcionamiento de los flujos de ingreso y gasto de la administración real.

El negocio con el capital privado tuvo como principal aliciente redimensionar el flujo monetario en los centros de gasto. Los aportes de dinero y la administración privada en manos de financieros poderosos lograron regularidad, rapidez de localización espacial y, prácticamente, plena disponibilidad de dinero para los pagadores del ejército. En sus aspectos principales, el sistema resultó muy beneficioso para solucionar los problemas de liquidez a corto plazo. Sin embargo, el destino de los recursos de la Monarquía a la financiación de una política militar con unas infraestructuras que beneficiaban a sectores mercantiles privados supuso el encumbramiento de los grupos sociales privilegiados que fueron imponiendo condicionantes al desarrollo de la dinámica política. Más aún cuando al control financiero se unió, en muchos casos, el control administrativo de oficios de gestión o cargos patrimoniales.

La Hacienda catalana reposó en este período sobre unas bases privadas a cuyo cargo quedó el suministro de materias primas, beneficiándose también de los gastos continuados del abastecimiento de las galeras, las fortificaciones o las tropas de paso hacia Italia. El control era mayor cuando se tiene en cuenta que, en determinadas coyunturas, eran los mismos agentes quienes aportaban el dinero que componía las partidas del cargo contable y aquellos que se veían favorecidos por los gastos, en cuanto proporcionaban mercancías de abastecimiento de tropas e infraestructura. Situados en este marco de estudio, conviene pormenorizar esta interrelación, para valorar correctamente la importancia

17 Ruiz Martin (1975), p. 458.

18 Braudel (1993), vol. I, pp. 595-598. 
de los créditos sobre Lyon, que considero el medio más complejo de contacto entre la Corona y el medio mercantil-financiero privado durante la época de Felipe II.

En cuanto a la explotación de los derechos patrimoniales del monarca, los grandes nombres del mundo de los negocios no se destacan por su participación ${ }^{19}$. Bernardi Granollachs sólo aparece como fianza en el contrato de arriendo de los derechos de la villa de Pons entre 1594 y 1597 . Entre 1552 y 1587, Damià Puiggener es fiador en la escritura de administración de las rentas reales de Tortosa, Torroella de Montgri y Pals, pero sin continuidad y sin aportes importantes de capital. Pau Puiggener es fiador también del arriendo de Torroella entre 1549 y 1550 . La tónica, pues, parece ser rehuir los ámbitos hacendísticos de escaso nivel financiero. Las grandes figuras, sin embargo, perseveran en el cuidado de las fortunas aristocráticas, para las que realizan tareas de gestión de créditos o de derechos y rentas jurisdiccionales. Tienen, asimismo, una participación decisiva en los arriendos de los derechos de la Diputación del General, una de las parcelas más productivas de beneficios de la época ${ }^{20}$.

Respecto al Real Patrimonio, un examen de la evolución de los derechos patrimoniales durante todo el siglo xvi y hasta mediados del xvil sólo permite percibir en la documentación administrativa el escaso valor pagado al Baile General por la cesión de la administración. Es a través de los papeles privados cuando las razones de este proceder se aclaran y se relativiza la despreocupación por el control legal de unos derechos y réditos que, en realidad, ya estaban plenamente integrados dentro de los parámetros de presión que los mercaderes podian aplicar sobre los organismos administradores de la Monarquia.

Por una parte, podía eludirse por fraude el pago de derechos. En 1556, un mercader prestigioso, Lluc Vilar, defrauda casi 400 quintales de hierro no declarados a la Bailia General, encargada del control de productos estratégicos a través del derecho de saca de «coses vedades» ${ }^{21}$. Si resultaba fácil esquivar los

19 Hernández (1995), pp. 244-245.

20 AHBC, not. Miquel Axada, Octavum manuale contractuum communium, 1591-1592, 1592-02-07; Francesc Reguer aparece como administrador de diversas castellanias en Cervera. También aparecen Francesc Reguer y Francesc Granollachs en el arriendo del derecho de carnes de la ciudad de Barcelona (Ibidem, Nonum manuale contractuum communium, 1592-1593, 1592-12.31). Véase también el libro de cuentas (Diario o Manual) de Frederic Roig i Soler entre 1584 y 1592, conservado en ACA (Archivo de la Corona de Aragón), AG (Real Patrimonio. Apéndice General), vol. 1075. Las referencias a la Diputación del General proceden de mis investigaciones en curso; en principio, véase ACA, G (Generalitat), vols. G.24/17a-i y G.24/18.22.

21 ACA, BG (Real Patrimonio. Bailía General), Procesos antiguos, leg. 1556-1557, proceso B; el pleito se complicó y aún se dirimía en 1559 , cuestionándose la eficacia de los guardas patrimoniales en este asunto (ibidem, leg. 1558-1559/1, proceso $O$ ). 
derechos a los mercaderes autóctonos, también lo fue para los extranjeros a partir de la simulación de nacionalidades de sus factores. Este procedimiento de representación o procura se generalizó aprovechando la coyuntura internacional y el cosmopolitismo de la Barcelona de la época, ruta obligada hacia Italia y Europa. De esta práctica se hace eco el testimonio de Joan Vinyes, que por espacio de casi 15 años había arrendado los derechos de lezda y sobre italianos en Barcelona, cuando reconocía que en ese tiempo había tratado en múltiples ocasiones con Damià Puiggener sobre «robes que li eren stades comanades per ytalians». En todo caso la proporción de mercaderes representados y su entidad es desconcertante, como en 1583 cuando una negativa a pagar el derecho italiano lleva a demostrar que la propiedad efectiva de la voluminosa mercancía defraudada era de negociantes tan conocidos como Baltasar y Antonio Suárez, Juan de Lago o Antonio Gutiérrez, profusamente destacados en los indices de las obras de Ruiz Martín ${ }^{22}$.

Simón Ruiz, por su parte, siempre aprovechó los servicios de sus conocidos en viaje por Cataluña. Es precisamente un estudio de su correspondencia lo que aporta detalles inéditos sobre el amplisimo margen de maniobra del mundo de los hombres de negocios en Cataluña entre 1564 y 1595, fechas entre las que se conservan cartas dirigidas desde Cataluña al mercader castellano ${ }^{23}$. Aparte de las negociaciones de los factores del propio Ruiz, las cartas describen a Barcelona y los puertos catalanes de Roses y Tarragona como rutas de tránsito de las galeras hacia Italia, cargadas del metal precioso que requería la Monarquía para sostener su politica europea. Son numerosas, en este sentido, las informaciones sobre el desarrollo mercantil y financiero o las referencias a los gastos de la Monarquia en sus estancias con la corte en el Principado 24.

La lectura de la documentación de una serie de estrategias comerciales y de relaciones de favor entre mercaderes y entre éstos y los organismos administrativos públicos pone en conocimiento del investigador una situación rica y complicada en la que la sujeción del sistema fiscofinanciero de la monar-

22 ACA, BG, Procesos antiguos, legs. 1560/1 (proc. J) y 1583 (proc. F). Sobre la identidad de los citados, véanse los índices en Ruiz Martín (1965).

${ }^{23}$ Diego Brochero le garantiza espacio para transportar mercancías en las galeras (D. Brochero a S. Ruiz, Palamós, 1589-04-17; AHPUV, SR, 133/211); años antes, Cristóbal Brizeño le negocia licencias de saca ante el virrey de Cataluña (C. Brizeño a S. Ruiz, Tarragona, 1564-01-04; AHPUV, SR, 2/227).

24 «Estas galeras llevan grande riqueza para Su Majestad y ottros particulares y no menos es la que aquy a dexado la corte porque se an pagado bien los catelanes de qualquier cossa que nos ayan vendido y vendan por donde consta clarissimo que ay se da todo de balde en comparación de aquí, escribe Francesco Lamberti a Simón Ruiz (Barcelona, 1585-06-10; AHPUV, SR, 98/34). 
quía a la voluntad de los lobbies privados es la tónica general. Asimismo, únicamente la organización internacional de los financieros catalanes aseguraba a Barcelona o a la Diputación el sostenimiento económico de síndicos y embajadores en la corte o en Roma. Para Barcelona, en las coyunturas de 1577. 1578 y 1582-1584, fueron vitales las relaciones cambiarias con hombres de negocios en Lyon para el pago de los trigos comprados en Génova, Sicilia o Francia ${ }^{25}$.

Otro aspecto, la dependencia monetaria de la economía privada de los virreyes, por ejemplo, se aprecia con gravedad y apuros en los tempranos contratos de préstamos hechos por algunos comerciantes catalanes a los lugartenientes desde mediados de siglo ${ }^{26}$. Las contraprestaciones no se hicieron esperar. La mayor parte de cargos patrimoniales (gestión de rentas y derechos del rey) de importancia en Cataluña estarán en manos de poderosos financieros, directa o indirectamente, entre 1516 y $1640{ }^{27}$.

Cuando muere el pagador García de Velasco, por ejemplo, el mercader Pere Cassador asume, como fiador que era de las finanzas del difunto, la administración en albacea de los fondos ${ }^{28}$. A la muerte de Pere Bernat Codina, regente de la tesorería y prestamista, se encuentran en su poder muchas referencias y notas respecto a copias de letras de cambio libradas sobre Lyon a pagar por las sociedades catalanas alli establecidas. Las cantidades a desembolsar eran importantes, en torno a 814.040 sueldos. Lamentablemente no se conservan los libros de contabilidad del regente de la tesorería, que hubieran demostrado, quizá, la financiación de la tesoreria catalana a través de un sistema crediticio parecido al utilizado por los pagadores. En el mismo inventario de los bienes de Codina, alguna de las letras de cambio transcritas se acompañan de un acuerdo privado que especifica la cotización máxima a que serán pagados los retornos «no obstant qualsevol relació que vinga de dita fira de Reys per assi”, se aclara. El papel de los bancos y cambios particulares en todo momento era crucial, manejando más dinero en este proceso que la Tabla de Barcelona al ser los mismos banqueros quienes proporcionaban los créditos y, en la práctica, establecían las modalidades de reembolso. De sus tres cuentas abiertas en Barcelona en 1584, por ejemplo, P. B. Codina tenía en la banca Taver-

25 Pueden comprobarse las listas de cambios puntuales recopiladas en la correspondencia enviada por la ciudad: AHCB (Archivo Histórico de la Ciudad de Barcelona), Consell de Cent, vols. VI-60 (f. 174, 180v-181, 189v) y VI-63 (f. 74v-75).

26 AHPB (Archivo Histórico de Protocolos de Barcelona), not. Nicolau Molner, Quintum manuale contractuum communium, 1559, escritura de crédito y debitorio concertado por el virrey con Guillem Guirzes (1559-05-29).

27 Hernández (1995), pp. 249.252.

28 AGS, CMC (Contaduría Mayor de Cuentas), 2.a época, leg. 367. 
ner 176.934 s., en la banca Puiggener 120.964 s., mientras que en la Tabla sólo contaba con $6.211 \mathrm{~s} .{ }^{29}$.

No entraremos ahora en las cuestiones concretas de suministros, aunque convenga destacarse - pues se le cita más adelante- el caso de Francesc Reguer, que simultanea los créditos al pagador con la administración de trigo siciliano comprado por la Real Hacienda para ser distribuido en Cataluña desde 1584. O el caso del pagador García de Velasco, participante en negocios de fletes y carga de mercancias y viveres ${ }^{30}$.

En todos estos episodios la presencia de grandes comerciantes fue destacable. En el caso de los Granollachs, aparecen relacionados con contrabando de monedas en muchas ocasiones. En 1577, por ejemplo, participan en una operación de contrabando de azafrán y reales junto a otros destacados mercaderes de Barcelona. No es arriesgado dar pleno valor a informaciones aisladas y generalizarlas, pues son testimonios de documentación no administrativa. Según los Bonvisi, que escribian a Simón Ruiz en 1579, los Granollachs se habian especializado en el tráfico de reales entre Barcelona y Marsella-Lyon, parece que con sobornos y evitando el pago de derechos del General de Cataluña ${ }^{31}$. El espacio mercantil catalán, progresivamente extendido a lo largo del siglo, en el aprovechamiento de la demanda y el gasto de la monarquia no se limitó a Cataluña. Es el caso de la compañia catalana de Baldiri Safont, establecida en Lisboa y que se beneficia del suministro de viveres a parte de la Armada que participa en la empresa contra Inglaterra ${ }^{32}$.

Como conclusión de este apartado puede destacarse el elevado grado de control por parte de los agentes privados sobre la infraestructura de gastos e ingresos de la monarquia en Cataluña. Resulta innegable, además, señalar el gran edificio financiero y no tan sólo mercantil en que se movían estos hom-

29 AHPB, not. Francesc Pedralbes, «Inventarium haereditatis et bonorum Petrus Bernat Codina» (1584). Las relaciones entre la Tabla de Barcelona y los bancos privados fueron, además, especialmente conflictivas en la segunda mitad del siglo xvi; Adroer/Feliu (1989), pp. 51-54.

30 ACA, AG, vol. 116 (Francesc Reguer); AHPB, not. Nicolau Molner, Secundum manuale contractuum communium, 1557-1558, 1557-07-16 y 1557-08-23 (García de Velasco).

${ }^{31}$ AGS, Estado, leg. 336, f. 160 (año 1577); AHPUV, SR, 54/19: los Bonvisi a Simón Ruiz (Lyon, 1579-02-02). Más detalles sobre el contrabando de dinero pueden verse en una comunicacion inédita: Hernández (1995b).

32 AHBC, not. Miquel Axada, Tercius liber procuracionum et protestuum, 1591-1592, 1592-02-22; AGS, GA (Guerra y Marina), leg. 189, f. 22-23, 40 y 95. Manuel Gracia ofrece más datos sobre mercancías catalanas y los contratos del proveedor Francisco Duarte con Safont entre 1587 y 1588 (Gracia, 1986: 56, 62 y 77). Baldiri Safont y Pau Soler fueron los factores en Lisboa de una sociedad participada, también, por Pau Puiggener y Joan Serra entre 1585 y 1597 (ACA, Monacales. Universidad, vol. 145). Un ejemplo de relaciones más cosmopolitas ha sido estudiado en Conde (1990). 
bres de negocios o su amplio margen de maniobra gracias al control de los mecanismos de gestión de tesoreria. En cuanto los mismos financieros ocupaban cargos de responsabilidad hacendística, era muy probable que el dinero -aunque acabara finalmente en las cajas de los contadores y en los arqueossirviera antes de fondo de actividad especulativa en los negocios privados de los oficiales que de medio de pago directo de las partidas administradas. Todo este conjunto de factores posibilitaron que, en todo momento, las técnicas financieras privadas y los mecanismos de especulación asociadas a ellas se pusieran al servicio de las necesidades hacendísticas del monarca. De estas técnicas o modalidades de negociación aquella que presentó rasgos de mayor elaboración especulativa fue la de provisión de dinero efectivo al pagador del ejército y de las galeras del Principado.

\section{LA MECÁNICA E INSTRUMENTACIÓN DE LAS OPERACIONES CAMBIARIAS ENTRE BARCELONA Y LYON}

A diferencia de un mercado de cambios ideal, que se estableceria entre Barcelona y Lyon como necesario por la existencia de una corriente comercial entre las dos ciudades y que vendría a compensar los desajustes en importaciones o exportaciones entre ambas plazas a través de una tercera ${ }^{33}$, la situación del mercado catalán de cambios en su articulación privada y en relación con la Corona ofrece unos caracteres concretos que favorecerán su uso por los mercaderes como marco de relaciones económicas con la monarquía:

a) Una gran presencia de la especulación en los tratos; percibida a través de ejemplos de operaciones privadas. La prohibición del interés en los préstamos hizo recurrir a la negociación de cambios ficticios mediante letras libradas sobre la plaza de Lyon. Una estrategia similar a la que aqui analizo fue expuesta por H. Lapeyre y Ruiz Martín respecto al mercado de cambios valenciano en el siglo XVI en sus análisis de los mecanismos especulativos ${ }^{34}$. No hacían referencia, sin embargo, a la posible conexión con las finanzas públicas de estas estratagemas privadas consistentes, en algún extremo según este último autor, en «letras de cambio que no se movian del cajón en que se guardaban, hasta que maduraba el plazo de feria en feria y se hacia el cómputo como si hubiesen ido o vuelto». Lamentablemente, la no conservación de los fondos docu-

33 Lapeyre (1982), pp. 304-305.

34 Lapeyre (1978), pp. 130 y 135; Lapeyre (1982), pp. 303-325; Ruiz Martin (1992), pp. 208-209. 
mentales de la Taula de Canvi barcelonesa para los siglos XvI-XviI impide establecer comparaciones precisas con el mercado de cambios de Valencia, más allá de las referencias que aquí estudiamos, procedentes concretamente de documentación oficial de la Real Hacienda ${ }^{35}$.

b) La utilización de una plaza extranjera como Lyon, de modo preferencial. La mayor parte de los cambios que establezcan los oficiales patrimoniales serán girados sobre la plaza francesa y librados en agentes comerciales catalanes radicados en ella. Hacia 1585 las compañías catalanas en Lyon eran: Bernardi, Francesc \& Joan Granollachs, Damià Berenguer Puiggener \& Cía., Francesc Galceran Font \& Miquel Calopa y Onofre Claveria, Antoni Casanova \& Jaume Llebre; todas ellas posibilitarán las estrategias desarrolladas por la «ingenieria financiera» de la época. Respecto a Lyon, existieron corrientes comerciales de contacto fructífero con Barcelona: junto al tradicional comercio de tejidos, cochinilla y azafrán destacaron otras mercancias. M. Peña, por ejemplo, ha estudiado el mundo librero de la Barcelona de la época, inmersa en la dinámica de un comercio editorial en la que Lyon es un centro de primer orden ${ }^{36}$.

La necesidad de crédito por parte de la Real Hacienda en Cataluña condujo a desarrollar una serie de contratos y escrituras de obligación que, enmascarados en el documento de las letras de cambio, actuaban como verdaderos préstamos con interés. Pueden considerarse más operaciones financieras que comerciales, lo que no obstó para que toda la red de establecimientos en Lyon prosiguiera en sus negociaciones privadas mercantiles a lo largo de esta época. Pese al componente especulativo incuestionable de estas operaciones crediticias, las compañias catalanas permanecian en Lyon, todavia, en mayo de 1590 , cuando sólo restaban en la ciudad los tratantes «fundatos en negoçios de mercaderias», como escriben los Bonvisi a Simón Ruiz; y tenemos noticias de su mantenimiento en las décadas primeras del siglo XVII ${ }^{37}$.

c) La disposición particular de instrumentos de crédito complejos que relacionan, de un modo a mi entender original, a la monarquía con los financieros catalanes. Era una perspectiva no contemplada hasta ahora por la historiografía el investigar las posibilidades de suplir la falta de numerario por los pagadores en Cataluña mediante las disponibilidades económicas catalanas.

35 Pueden ampliarse las referencias bibliográficas aquí aportadas con la consideración de operaciones similares practicadas en la financiación de actividades de abastecimiento urbano; Hernández Esteve (1992), pp. 55-76, pero también para hacer frente a necesidades hacendisticas en territorios no peninsulares durante el siglo xvi; Calabria, (1989), pp. 587-591. En todo caso, una de las conclusiones paralelas de nuestro estudio es aportar algunos datos sobre el inexcusable redimensionamiento del estudio de los circuitos cambiarios catalanes de los siglos XV-XVII.

36 Peña (1996), pp. 96-105.

${ }^{37}$ Lapeyre (1955), p. 459; Vilar (1968), pp. 314-320. 
Son contratos que han pasado desapercibidos por las dificultades metodológicas que comportan, pero que resitúan en una escala diferente y compleja las discusiones en torno a la contribución económica de Cataluña a la política del Imperio, pues mostrarian la trascendencia de una implicación parcial del mundo mercantil catalán en el sostenimiento de las operaciones militares de la monarquía; de la misma manera que se ha insinuado respecto a la contribución fiscal indirecta, pero destacable, representada por las licencias de propio uso concedidas a la saca de metal precioso ${ }^{38}$.

d) La rentabilización máxima de la infraestructura (bancos y compañias) aprovechada. La existencia de bancos privados (los principales eran los de Bernat Taverner y Damià Puiggener) en Barcelona y la simultánea presencia de mercaderes catalanes en Lyon son dos condiciones exigidas para la generalización y la regularidad de estas operaciones de crédito. Estas bancas privadas movilizaban la mayor parte del dinero frente a la Tabla de Barcelona que, pese a su prestigio, nunca fue un banco -en el sentido estricto de creación de crédito- y cuya administración fue muy conservadora, limitándose al papel de institución de depósito y giro de fondos.

Un manuscrito latino, conservado en un fondo misceláneo del archivo de la catedral de Barcelona, y un borrador de letras de cambio de la compañia Frederic Soler \& Joan Burguès, de Barcelona, han permitido captar la complejidad de las relaciones financieras y especulativas operadas mediante cambios entre Lyon y Barcelona en la segunda mitad del siglo xvI ${ }^{39}$. Ambos documentos enmarcan las operaciones mercantiles privadas mediante letras cambiarias en un panorama muy distinto al que pudiera sugerir un estudio superficial de las compañías comerciales de los grandes negociantes barceloneses. En sintesis, logran poner de manifiesto el alto contenido especulativo de parte de los contactos financieros a lo largo del siglo XvI.

Dentro de lo que el anónimo autor del tratado considera cambios, se detiene en los que eran más usuales en la Barcelona del siglo xvi: el cambio por letras o local, denominación acorde con el instrumento financiero y con la función de comunicación geográfica que comportaba. Siempre según el autor,

38 Hernández (1995b).

39 Archivo Capitular de la Catedral de Barcelona, Miscelanea, caja 8, doc. 11: «Brevis de cambiis tractatusm; manuscrito anónimo de la segunda mitad del siglo xvil, sin foliar, interesan especialmente los parágrafos 9 a 35. Parte del manuscrito reproduce, en catalán, ejemplos de operaciones financieras. El borrador de letras de cambio de la compañia de Joan Burguès y Frederic Soler i Roig, de fines del siglo XVI, está conservado en ACA, G, vol. V.69, e incluye varios despachos de ferias de Lyon. 
local porque era de lugar a lugar (v.g., de Barcelona a Roma) y por letras, porque éstas eran el instrumento de comunicación entre ambas localidades $(\$ 9)$. Siguiendo, en parte, a Acaci de Ripoll ${ }^{40}$, y a través de la presentación de modelos de relaciones, mediante las figuras clásicas del campsor y campsorius (ambos en Barcelona) y de los «agentes seu corresponsales eorum qui Lugduni commorantur» $(\$ 14)$, plantea distintas posibilidades de procedimientos especulativos que tienen su correlato práctico y documental en las abundantes referencias dispersas que aporta la documentación privada de los diferentes archivos barceloneses. $\mathrm{Y}$, de forma más interesante, en las cuentas de los pagadores de la Corona.

El tomador del dinero a cambio acordaba con el dador del dinero el libramiento de una letra de cambio por una determinada cantidad estipulada en escudos de oro en oro del sol (escudos de marco, si es antes de 1575) a pagar en alguna de las ferias que a lo largo del año se celebraban en Lyon. El tomador, en realidad, no tenia corresponsales (por tanto, ni cuenta efectiva ni dinero) en Lyon, por lo que debía aprovechar la red de agentes y crédito que, asentada por algunas familias mercantiles de Barcelona (Puiggener, Granollachs, Llebre, Casanoves, Font, Calopa), existía desde principios del siglo Xvi en la ciudad francesa. De esta manera, el dador del dinero a cambio proporcionaba corresponsales y crédito, a efectos puramente contables, en Lyon al tomador para que pudiera hacer efectiva la letra. El corresponsal en Lyon, mediante una letra de aviso, era advertido para que admitiera la letra, no la rehusara y se valiera de la manera que dispusiera en el documento el tomador («y posau-los a compte com se us dirà»). Éste especificaba posteriormente al corresponsal que la letra de cambio que se recibiera en Lyon la recambiara sobre él mismo (el tomador de Barcelona). El corresponsal recibía en Lyon las letras de aviso y la de cambio y, en virtud de todo el acuerdo subrepticio, en el libro de contabilidad que llevaba abonaba la cuenta del dador y adeudaba la cuenta del tomador, de acuerdo con las instrucciones recibidas $(\$ 20)$. La contabilización formal reflejaba, pues, que el cobrador de la letra en Lyon era el mismo dador del dinero en Barcelona, que mantenía cuenta corriente con el corresponsal en Lyon que a su vez, normalmente, era el librado de la letra.

De esta manera, el corresponsal o pagador de la letra asentaba en su libro diario una partida en que se daba por pagado al dador en virtud del adelanto de moneda que hizo en Barcelona al librador de la letra y, mediante una segunda partida - que anulaba la anterior puesto que el dador del dinero no recibia ninguna cantidad en la ciudad francesa-, se formalizaba el posterior li-

to Ripoll (1660), pp. $185-187$. 
bramiento por parte del corresponsal en Lyon de la letra de retorno. Porque, como en Lyon el corresponsal no tenía dinero del tomador, en ningún momento se había pagado la cantidad acordada en Barcelona ni interés alguno, salvo mediante la operación contable de haberle dado crédito al tomador para que el pago de la letra no fuera rehusado. Al objeto de que, realmente, el dador del dinero a cambio fuera pagado con intereses y para que el corresponsal o agente en Lyon recibiera su porcentaje de intermediario (provisión) éste, valiéndose de la orden que le había dado el tomador, formaba en Lyon otra cambio (y por tanto, recambio) por la cantidad recibida en Barcelona más los intereses pactados, el corretaje o las pérdidas por cambios contra el tomador inicial y a favor del dador. Esta segunda letra recibida en Barcelona podía ser pagada por el tomador del dinero a cambio. Si no, podía volver a recambiarse de feria en feria, como dice el autor, por diferentes plazas, haciendo «rodar» la letra por todas ellas $(\$ 23-25)$. En este sentido, era muy usual que las compañias libraran letras de cambio de capital de la sociedad a terceras personas para participar en los beneficios de este negocio, lo que condujo posteriormente a acusaciones de fraude ${ }^{41}$.

En estos cambios el interés nunca era fijo porque variaba de acuerdo con la abundancia o escasez de moneda en cada una de las plazas a que se dirigian las letras. A veces el campsor o el mercader que prestaba podia, incluso, perder dinero; otras, arrastrar en el recambio grandes beneficios ${ }^{42}$. Aunque esta operación de cambios es muy común en el siglo XVI, las circunstancias excepcionales que inciden en el caso catalán son la presencia de una práctica oligopolista por un grupo de preclaras familias comerciales barcelonesas y la realización de la maniobra sobre una plaza financiera tan destacada como Lyon, con total continuidad hasta los primeros años del siglo xvII. En lo que ahora más interesa, la importancia radica en una auténtica «ingeniería financiera» aplicada en los tratos de sostenimiento financiero de la Monarquía en Cataluña. Un edificio especulativo que se mantiene al margen de la mayor o menor importancia de Barcelona como plaza de cambios en la segunda mitad del siglo XV1 ${ }^{43}$.

41 Asi, en 1591 se acusaba a la compañia de los Puiggener de Lyon que «acostumava y ha acustumat de fer les remeses dels crèdits dels cambis de les quantitats que aquella donava per a Medina del Campo y altres parts a terceres persones y no a la companyia ni nom de aquella al que.s pot creure en frau dels crehedors de tota la companya» (ACA, BG, procesos antiguos, leg. $1591 / 4$, proc. A, f. $29 \mathrm{v})$.

42 Aqui radicaba la licitud de estos contratos de cambio, que no censura el autor del manuscrito, siempre y cuando no se conviniera el curso del escudo lionés por anticipado al retorno de la letra en Barcelona, ya que se trataria, entonces, de un cambio con la ricorsa; Noguera (1950), pp. $326-327$.

43 Vilar (1968), pp. 280-282. 
El control férreo de una serie de comerciantes y hombres de negocios sobre toda esta trama especulativa entre Barcelona y Lyon se puede plantear atendiendo a otras dos posibilidades contempladas en el tratado sobre cambios. Por una lado, siempre y cuando el tomador no quisiera «demonstrar-se en cosa ni en fer lletra de cambi ni de avís», porque no tuviera en Lyon crédito ni corresponsal o porque «no li està bé se sàpia pren diner a cambi», el dador asumía toda la operación individualmente. Libraba una letra, sobre sí mismo y a su favor, al corresponsal de Lyon y éste, de acuerdo, recambiaba para Barcelona con intereses y costes. En la ciudad catalana, el oculto tomador devolvía la cantidad estipulada con los réditos. De nuevo, resulta fundamental el carácter privado de las bancas de los cambistas-mercaderes $(\$ 26-32)$.

Por fin, otra posibilidad, deja ver claramente las tácticas de control. En este último caso descrito hay todos los elementos necesarios para un contrato lícito. El tomador del dinero a cambio posee en Lyon crédito y corresponsal, pero el dador no acepta comprar las letras salvo si son libradas sobre su propio agente en Lyon. El tomador, forzado por la necesidad, se ve obligado a convenir con los deseos del dador y se acomoda ante la imposibilidad de encontrar otras fuentes de financiación $(\$ 35)$.

Las referencias documentales que reflejan lo complicado de las argucias hacen que los mercaderes organicen sus libros en torno a «lletras de cambis que rematem per totes parts», «lletras de cambi que trayem» y «lletras de cambi que.m remeten». O de esta manera lleva sus cuentas Frederic Roig con Lyon; dador de dinero a cambio: letras sobre los Puiggeners o los Font \& $\mathrm{Ca}$ lopa utilizando su cuenta terceros; tomador: libra cartas a pagar a terceros sobre los de Lyon; o librado: letras de cambio enviadas desde Lyon, que vienen de feria especifican las cotizaciones y se pagan a Roig o a la sociedad que mantiene con J. Burguès.

La especulación se hace más evidente cuando se estudian algunas escrituras de protocolos. Aparece todo el esquema descrito y el añadido referencial que interesa, como cuando un tomador escribe que «y encara que en dites lletres de cambi degan per cambi fet ab mi, és la veritat que no li'n tinch pagat cosa ningunam. Efectivamente, sólo había llegado a un acuerdo para pagar la letra librada en Barcelona sobre Lyon, con una nueva letra al usado para Barcelona ( 30 dias) y cincuenta días más «y asò planament y mercantívoll sens da. nis ni despeses sues ni dilasió alguna» ${ }^{44}$. Esto también lo escriben los grandes negociantes. En palabras de Miquel Calopa, que reconocía haber comprado le-

44 AHBC, not. Miquel Axada, Octavum manuale contractuum communium, 1591-1592, papel suelto de 1592-05-06, escritura particular. 
tras sobre Lyon libradas contra la sociedad Miquel Calopa \& Francesc Galceran Font, «en dit cambi jo no y tinch sinó lo nom y que realment y de fet los diners y lo interès és de vós dit mossèn Jaume Caralps» ${ }^{45}$.

El retorno debía ser aceptado en Barcelona, pagando salario de procurador si se realizaba fuera de la ciudad; incrementado por los conceptos de corretajes, intereses pactados y perjuicios por cambios. Además el tomador prometia restituir toda cantidad de dinero («missiones, sumptus, expensas vel dampna aliqua patire vel sustinere contigerit») que debieran pagar los primeros dadores para exigir y cobrar la deuda en firme. Para mayor seguridad, el tomador ofrecía abonadores del compromiso ${ }^{46}$.

Aunque, en su obra acabada en 1655, Ripoll aportara más precisiones sobre el tema especulativo ${ }^{47}$, las referencias bibliográficas de época y actuales sobre la aplicación de estas actividades a las relaciones entre hombres de negocios y los organismos hacendísticos de la Corona en Cataluña son inexistentes. No obstante, los documentos contables de los pagadores, conservados en el Archivo General de Simancas, no dejan ningún lugar a dudas sobre la similitud de estrategias en la negociación privada y pública de los financieros catalanes.

El procedimiento puede quedar más claro mediante la exposición de una operación según criterios de un modelo de contrato de cambio ${ }^{48}$. Por orden del virrey el pagador Pedro de Ugarte (sustituto de Juan Ortega de la Plaza) recibió de Damià Puiggener 92.000 sueldos en Barcelona, en efectivo o a través de un banco de la ciudad. Interviniendo en el contrato el contador y veedor del ejército Pedro de Isunza, como contraprestación de este dinero tomado a cambio, el día 20 de febrero de 1585 Ugarte libró y entregó a Puiggener una letra por valor de 4.000 escudos de oro (al cambio concertado de 23 sueldos por escudo de oro del sol), pagadera en la feria de Lyon. A este nivel ya aparecen dos de las figuras acostumbradas: el dador del dinero a cambio (Puiggener) y el librador de la letra (Ugarte). En todo caso hay que tener en cuenta la intervención fraudulenta que supone que el cobrador de la letra en

45 Ibidem, escritura de fecha 1592-06-09.

46 AHBC, not. Miquel Axada, Secundum manuale contractuum communium, 1585-1586, escrituras de fechas 1586-01-21, 1586-03-31, 1586-04-09 y passim; son diferentes ejemplos.

47 Este autor define como cambio seco aquel en el que «qui dat literas non habet factorem, nec campsorem in loco ad quem litterae dirigintur, nec merces ex quibus litterae soluantur, hoc enim casu usurae, sive interesse non debetur; quia contractus est usurarius»; para aclarar luego un proceso especulativo similar al descrito en el articulo: "solet etiam evenire, quod aliqui dant pecunias aliquibus negotiatoribus sub pacto, quod certam pecuniae summa accipiant et negotiabunt salvo semper capitali, et quod predictis dantibus, ad cambium certis temporibus prestabunt aliquid pro interessem, trato que este autor considera inválido; Ripoll (1660), pp. 185 y 191.

48 Hernandez Esteve (1988), pp. 245-248; Conde (1993). 
Lyon sea el mismo Damià Puiggener y el librado la compañía de Bernardí, Francesc y Joan Granollachs de Lyon, los cuales han acordado con antelación el incumplimiento del contrato de cambio.

De esta manera, la letra fue enviada a Lyon sobre los Granollachs para asentarla en cuenta propia de Puiggener. Los Granollachs, atendiendo al pacto previo, rechazaron el pago de la letra por hallarse sin activos reales (mercancías) o financieros del librador. Se procedió, pues, a la formalización de una letra de retorno sobre Barcelona en la que el librado era Ugarte y el cobrador Puiggener. Pero esta letra girada a Barcelona se cotizó de acuerdo con el valor en sueldos barceloneses por cada escudo del sol de los últimos pagos de feria en Lyon. En este caso particular, la letra de 4.000 escudos vino a razón de 23,58 sueldos por escudo. Cuando se formalizó la libranza en Barcelona, el día 31 de agosto de 1585 , se pagaron a D. Puiggener 98.333,33 sueldos, más 12,25 sueldos por las costas del protesto. El pago efectivo, realizado tres días después, supuso unos intereses para D. Puiggener del 10,68\% de beneficios en el plazo de medio año ${ }^{49}$.

El circuito de ida y retorno es fundamental a la hora de comprender correctamente el mecanismo. Como instrumento de negociación privada, la letra de cambio era el medio de establecer relaciones financieras entre las sociedades catalanas radicadas en Barcelona y sus filiales de Lyon, cuando el librado era el corresponsal del librador. Sin embargo, como instrumento de especulación que escondía un contrato de crédito entre los oficiales reales y el comerciante catalán, la letra aparecía en las cuentas de los pagadores como un medio fraudulento en cuanto se simulaba que el oficial (el librador) era acreedor del librado o, entiéndase, que aquél habia hecho con anterioridad una provisión de fondos en Lyon a éste.

La protestatio estaba, en ocasiones, en la base del giro de recambio provocado por la reclamación del cobrador y por la negativa o inhibición de pago del librado. A diferencia del proceso descrito en el tratado de cambios, en las negociaciones con el pagador podía simularse una letra en Lyon a girar sobre Barcelona, pero lo más habitual era el protesto por impago de la letra venida de Barcelona. Es este protesto o el recambio lo que aparece en las cuentas de los pagadores, constituyendo en las datas partidas que gravaban dañosamente los balances contables. Dada la necesidad urgente de efectivo, se solicitaban créditos a banqueros catalanes que se ofrecían a negociarlos mediante el simulacro de librar letras de cambio sobre corresponsales propios con el acuerdo de protestarlas o recambiarlas. Se formaba, entonces, un circuito cerrado que

${ }^{49}$ AGS, CMC, 2." época, leg. 376; datas de maravedis tomados a cambio. 
obligó en situaciones extremas a que el virrey autorizara créditos para hacer frente a los pagos de cambios que volvian de las ferias francesas.

\section{TRAYECTORIA DE LOS CAMBIOS CON LOS AGENTES DE LA CORONA}

A través del estudio de las cuentas de los pagadores del ejército, he localizado un total de 81 partidas referidas a contratos de créditos mediante letras de cambio, por un total de 7.588 .355 sueldos barceloneses ${ }^{50}$. Respecto a la negociación de plazas, restando dos contratos en los que no se especifica el lugar del libramiento, el valor particularizado según la plaza sobre la que se giran las letras de cambio es el que se presenta en el cuadro 1 :

\section{CUADRO 1}

Dineros tomados a cambio y anotados en el cargo de los pagadores (1566-1587)

\begin{tabular}{|c|c|c|c|c|}
\hline \multirow[b]{2}{*}{ Plaza } & \multicolumn{2}{|c|}{ Letras } & \multicolumn{2}{|c|}{ Cantidad cargada } \\
\hline & Número & Porcentaje & Cantidad (sueldos) & Porcentaje \\
\hline Lyon .... & 49 & 60,50 & $4.817 .531,97$ & 63,49 \\
\hline Valencia $\ldots \ldots \ldots \ldots \ldots \ldots \ldots$ & 13 & 16,00 & $427.236,00$ & 5,63 \\
\hline Medina $\ldots \ldots \ldots \ldots \ldots \ldots \ldots$ & 9 & 11,00 & $1.443 .680,22$ & 19,02 \\
\hline Madrid...$\ldots \ldots \ldots \ldots \ldots \ldots \ldots$ & 4 & 5,00 & $167.400,00$ & 2,21 \\
\hline Zaragoza $\ldots \ldots \ldots \ldots \ldots \ldots \ldots$ & 2 & 2,50 & $93.576,00$ & 1,23 \\
\hline Palma de Mallorca $\ldots . . . \ldots \ldots . .$. & 2 & 2,50 & $80.000,00$ & 1,05 \\
\hline No especificada $\ldots \ldots \ldots \ldots \ldots . . . .$. & 2 & 2,50 & $54.331,00$ & 0,72 \\
\hline Total $\ldots \ldots \ldots$ & 81 & 100,00 & $7.588 .355,19$ & 100,00 \\
\hline
\end{tabular}

FUENTE: vid. nota 50.

Aqui sólo nos ocuparemos de las letras de cambio libradas en las ferias de Lyon. De todos estos contratos únicamente contamos con las partidas asentadas en las cuentas de los pagadores, por lo que resulta muy difícil identificar los distintos individuos que componían los diferentes vértices del contrato y que constarian en las letras de cambio originales. Sin embargo, queda perfecta-

so AGS, CMC, 1." época (legs. 1021, 1037, 1117 y 1522) y 2." época (legs. 368,471 y 473 ). 
mente clara la supremacia de las ferias de pagos de Lyon como lugar de libramiento de las letras negociadas en Barcelona. Una importancia cualitativa y cuantitativa respecto a las demás plazas peninsulares.

Sobre los mercaderes favorecidos por estas operaciones, su análisis debería hacerse desde dos perspectivas. Por una parte, aquellos que actúan como dadores de dinero a cambio. Esto es, quienes prestan el dinero al pagador o a su representante en Barcelona. Por otro lado, los banqueros en Barcelona y los corresponsales en Lyon que posibilitaban la ejecución de los acuerdos tácitos comunicados mediante cartas de aviso. El resultado del estudio de los principales financieros que negocian con la monarquía mediante créditos acordados con letras de cambio singulariza un grupo de diez personas, tal y como puede observarse en el cuadro 2 :

\section{CUADRO 2}

Principales financieros que daban dinero a cambio (1566-1587)

\begin{tabular}{|c|c|c|c|c|}
\hline & $\begin{array}{l}\text { Créditos totales } \\
\text { (sueldos) }\end{array}$ & $\begin{array}{c}\text { \% sobre } \\
\text { total }\end{array}$ & $\begin{array}{l}\text { \% sobre } \\
\text { Lyon }\end{array}$ & $\begin{array}{c}\text { Lyon sobre } \\
\text { total }\end{array}$ \\
\hline P. Ferreres .. & $2.592 .280,30$ & 34,16 & 30,55 & 56,78 \\
\hline D. Puiggener . . . . . . . . . . . . . . & $1.884 .980,00$ & 24,84 & 20,75 & 53,03 \\
\hline F. Reguer $\ldots \ldots \ldots \ldots \ldots$ & $919.187,23$ & 12,11 & 17,92 & 93,91 \\
\hline J. Rovirola & $494.775,00$ & 6,52 & 7,78 & 75,75 \\
\hline J. J. Gener ...... & $249.175,00$ & 3,28 & 5,17 & 100,00 \\
\hline B. Taverner .......... & $232.000,00$ & 3,06 & 3,32 & 68,97 \\
\hline M. Maduxer .. & $178.642,00$ & 2,35 & 2,76 & 74,49 \\
\hline J. Sauri $\ldots \ldots \ldots \ldots$ & $155.024,00$ & 2,04 & 0,00 & 0,00 \\
\hline B. y F. Granollachs & $118.290,81$ & 1,56 & 2,46 & 100,00 \\
\hline G. Guirzes ........ & $106.788,00$ & 1,41 & 0,00 & 0,00 \\
\hline Total ..... & $6.931 .142,30$ & 91,33 & 90,71 & \\
\hline
\end{tabular}

FUENTE: vid. nota 50.

La muestra es representativa, porque en ella se recoge el $91,33 \%$ del total de créditos contratados por los pagadores con letras de cambio a pagar sobre cualquiera de las plazas, así como el $90,71 \%$ del valor de las giradas a ferias de Lyon. De ellos, el mercader Pere Ferreres proporcionó un 34,16 de los créditos totales y un 30,55 de las cantidades en letras giradas sobre Lyon. Si se analiza este segundo cuadro se comprobará, además, el grado de control finan- 
ciero que pudieron ejercer Pere Ferreres, Damià Puiggener y Francesc Reguer en los contratos con los pagadores. Este trío proporcionó el $71,11 \%$ del dinero total cargado a los pagadores y el 69,22\% del girado por cambios sobre Lyon.

Considero indicativo del grado de especialización el que en el caso de todos los financieros que participan en cambios con Lyon, sobre el total de numerario negociado en diversas plazas, la cantidad que destinan a giros sobre la ciudad francesa supere el cincuenta por ciento (y signifique el ciento por ciento de los contratos efectuados en el caso de Jaume Joan Gener y de los Granollachs). En cuanto a estos últimos financieros, no es casual que sus factores en Lyon sean de los más activos a la hora de situar pagos.

Este segundo grupo de financieros, los banqueros barceloneses (D. Puiggener moviliza por terceras personas en su banco sólo 654.657 sueldos, frente a los 3.614.846 que gestiona B. Taverner) o las compañias de Lyon, junto con los corredores de oreja también repercutirian su actividad en daño de la pagaduria, siendo todavía más difícil de precisar sus porcentajes particularizados de ganancia.

Porque hasta aquí se está hablando en todo momento de dadores de dinero a cambio aunque sólo se han proporcionado los importes de los créditos que solicitaba el pagador por orden del virrey en Barcelona. Respecto a los desembolsos, en los que los dadores primitivos eran los cobradores, si bien se hacen explícitas en las partidas de los descargos o datas las cantidades pagadas a los financieros catalanes, se ha de tener presente que en ningún momento se ha podido trabajar con una plena seguridad de equivalencias entre conceptos de entrada-cargo y de salida-data.

Conviene recordar los complejos sistemas de las cuentas de los pagadores que exigen mucha atención en el análisis metodológico. Efectivamente, los créditos suponen un porcentaje altísimo del cargo normalmente. Siguiendo las no concluyentes cifras aportadas por los cargos y las datas, para el pagador Antonio Enrique sobre un total de cargo de $191.726 .823,5$ maravedís, se calcula un cargo subtotal de cambios de 75.134.976,5 maravedís entre 1568 y 1571 . Lo que supondria que el dinero tomado a cambio era el 39,19\% del cargo del pagador. Si se examina el apartado de la data, el reintegro de los cambios y créditos a corto plazo alcanza un $49,84 \%$ de la data global $5 !$.

\$1 A todo esto cabe además considerar que los créditos conseguidos mediante operaciones cambiarias sólo resolvian coyunturas puntuales de falta de liquidez, pues los plazos de devolución eran relativamente breves. Una situación de urgencia de numerario conducia al libramiento de letras de cambio sucesivas, lo que provocaba la multiplicación de los intereses a desembolsar. La deficitaria estructura financiera se explica por la falta de ingresos regulares, más allá de las remesas procedentes de Castilla, de los pagadores en Cataluña durante la segunda mitad del siglo xvı. Por ello, los mismos porcentajes de dinero tomado a cambio, posiblemente, están magnificados en algunos años por el efecto del eslabonamiento de unos créditos con otros. 
Ahora bien, estas cifras deben contrastarse con otras que respondan a la realidad contable de una hipotética caja de pagaduría. De este modo se podría examinar el total del cargo y descargo realizando una eliminación aritmética del numerario que el pagador se ha limitado a transferir (hacia las fortalezas de $\mathrm{Ba}$ leares, respecto a las que actúa de intermediario) o a desembolsar sin gestion propia (galeras) respecto al numerario que sería considerado propio de la pagaduría. Manejando sólo los capítulos de gasto e ingreso que guardaran estricta relación con Cataluña, los porcentajes de créditos se apreciarían siendo de hasta el $54,02 \%$ del total de los cargos y el $60,58 \%$ del total de descargos. Desde esta perspectiva, al menos entre 1568 y 1571, la pagaduría catalana sería fundamentalmente un órgano público sostenido por el capital privado barcelonés 52 .

Pero además hay otros mecanismos de crédito que no pueden adecuarse a un estudio común con las letras enviadas a la ciudad francesa. Por una parte, la correspondencia de Ruiz es muy explícita sobre las letras de cambio para Madrid, cambios «forzosos» para hacer frente a los gastos de representantes ante la corte o los viajes a Castilla o Roma; como ocurria con el Consell de Cent o la Diputación del General ${ }^{53}$. Por otro lado, no pueden asimilarse al proceso descrito operaciones como la de los 7.480 .000 maravedis que recibió el pagador Garcia de Velasco a través del banquero Damià Puiggener en Barcelona por una cédula de Joan y Pau Sauri desde Madrid el año 1575. Velasco había administrado por créditos con particulares un total de cargo de $7.726 .500 \mathrm{ma}$ ravedís que supusieron un desembolso global de 8.761 .313 maravedis, con un interés del $11,3 \%{ }^{54}$.

Todas estas operaciones menudearon y son necesarios muchos estudios para controlar el desarrollo cotidiano de este proceso tan jugoso en beneficios para los hombres de negocios. En este sentido, la utilización de los documentos de la Contaduría Mayor de Cuentas no agota las perspectivas futuras de investigación. Se encuentran préstamos y créditos a depósito dispersos. El duque de Terranova, por ejemplo, tomó a cambio 40.500 ducados $(15.187 .500 \mathrm{mrs}$.) en Barcelona el 24 de setiembre de 1582, mediante una letra dirigida a pagar por el tesorero Juan Fernández de Espinosa en Medina a 20 días a Pau Saurí, por tantos recibidos en Barcelona de Damià Puiggener por 1.281.600 sueldos en ropa, bizcocho y vituallas. La libranza de pago se haría en parte sobre la

52 AGS, CMC, 1." época, leg. 916.

${ }_{53}$ Pere Joan Casademunt a S. Ruiz (Madrid, 1581-03-15; AHPUV, SR, 65/239); Francesc Creus a S. Ruiz (Barcelona, 1573-02-24; ibidem, 18/34); Fray Andrés de San Román a S. Ruiz (Montserrat, 1572-11-11; ibidem, 16/178).

st AGS, CMC, 2. época, leg. 367: «Relaçión, tanteo y razón de la quenta de García de Velasco...»(1575-1577). 
Cruzada de Aragón y Cataluña y, en parte, sobre el arca de tres llaves, a razón de $10 \%$ anual de intereses ${ }^{55}$. En todo caso, aquello que procuramos destacar es que ninguno de los contratos de cambios estudiados se desarrolla de manera que no intervenga algún elemento desestabilizador en el pago de la letra. Esto es, siempre se desembolsan de acuerdo con protestos y recambios de las letras originalmente emitidas en Barcelona sobre Lyon.

En los pliegos de descargo de los pagadores para 1584-1585 se ajustan los pagos de los créditos contraidos en los años anteriores. Resulta muy difícil distinguir los beneficios pormenorizados según los cargos de las letras. De este modo, a Damià Puiggener, por libranza del 17 de marzo de 1584, se le pagan $154.000 \mathrm{~s}$. que son únicamente un anticipo a cuenta para que espere sin actuar judicialmente el final de los pagos de feria y se atenga al cumplimiento de los intereses que se habian concertado ${ }^{56}$.

En otro caso, el virrey conde de Miranda tomó una partida inicial de 11.428 escudos de oro a cambio de D. Puiggener el año 1584 en letras a pagar en Lyon y a retornar sobre Barcelona. En el momento de los pagos en Barcelona, el oficial real se encontró sin fondos y, debiendo hacer frente a los desembolsos «por no haver dineros para los pagar en su poder», volvió a tomar la cantidad adeudada en letras de cambio («se rrecambiaron») para Lyon el 8 de junio de 1584. La cantidad se volvió a recambiar por falta de dinero para Lyon el 5 de octubre del mismo año, incrementada con los intereses del cambio, los recambios, corretajes y costas de protestos. En cada uno de estos intermedios entre libramiento de letras, el financiero catalán recibió pequeñas cantidades de dinero a cuenta, más los intereses del tiempo transcurrido entre el plazo en que se debian cobrar las letras y el pago efectivo, según un baremo establecido por la Lonja de Barcelona 57.

Además, en alguna ocasión, para pagar las letras llegadas a vencimiento, se hacian nuevos contratos de cambio. En los pagos de las letras vueltas de Lyon se advierte que algunos cambios no son más que el producto de recambios de operaciones anteriores (así se hace constar «tomó y recambió»). Un ejemplo excepcional (véase el apéndice) lo representan los 1.088.441,30 sueldos cambiados sobre Lyon con Pere Ferreres el 6 de julio de 1569, tomados para pagar las letras vencidas venidas desde Lyon contra el pagador en Barcelona.

Pero, si no, ¿cuál fue el volumen, la cuenta exacta, de las operaciones?, ¿cuáles fueron las repercusiones de estos contratos sobre la Hacienda Real? He-

5s AGS, DGT (Dirección General del Tesoro), inventario 24, leg. 570: Duque de Terranova. Capitán General del Prinçipado de Cataluña. Cargo.

56 AGS, CMC, 2" época, leg. 376.

57 Ibidem, descargo de maravedis tomados a cambio; libranza de 26 de octubre de 1584. 
mos recogido varios testimonios muy explícitos que pueden aportar alguna respuesta.

Según el despacho de deudas de cambios de 1567 elaborado por el pagador Pere Cassador, los oficiales reales habían negociado contratos de crédito a través de Valencia (a pagar en Barcelona) y de Barcelona (a pagar en las ferias castellanas y de Lyon) con hombres de negocios catalanes, fundamentalmente ${ }^{58}$. A pagar en Barcelona un total de 246.878 s., con los siguientes beneficiarios: Pere Ferreres (158.718 s.), Francesc Cassador (8.816 s.), Bernat Taverner (79.344 s.). Todos estos contratos resultaban de cambios tomados en Valencia con el mercader Miquel Salvador y corrian con un tipo mensual de interés del $1 \%$ hasta la liquidación efectiva. A pagar en feria de Todos los Santos en Lyon, se anotaban 2.000 escudos de marco por un cambio realizado con $\mathrm{Mi}$ quel Creus en Barcelona el 6 de junio de 1567, sin poderse especificar la cotización por faltar los despachos de feria. Respecto a los pagos de las ferias de octubre de 1566 en Castilla, también sin despachos de feria que proporcionaran las cotizaciones, se anotaban 85.560 s., repartidos a cobrar entre Joan y Pau Saurí, Miquel Maduxer y Pere Joan Casademunt. Finalmente, para pagos de Reyes de Lyon, se adeudaban 23.000 escudos de marco tomados a Pere Ferreres, Francesc Reguer y Josep Rovirola el 10 de octubre de 1567.

Otro informe dirigido al Consejo de Hacienda del año 1575 advertía de las pérdidas financieras elevadísimas que provocaba el sistema de subvención de los gastos de la administración bélica de la Pagaduría a través de los contratos de préstamos acordados mediante letras de cambio a pagar en Lyon. De tres cambios establecidos con los Puiggener y los Rovirola por valor original de $311.520 \mathrm{~s}$. se habia reembolsado un total de $326.380 \mathrm{~s}$. (casi un $5 \%$ de media de intereses). Uno de los cambios, el establecido con Pere y Miquel Rovirola por un valor de 2.000 escudos de marco a pagar en la feria de Reyes de Lyon de 1575, había supuesto una devolución por Antonio Enrique, pagador del ejército en el Principado, de un $11 \%$ de intereses y costas debido al recambio venido desde Lyon a Barcelona. Sólo en el plazo de dos meses y medio se habia concertado el trato, habian vuelto varias letras de cambio y se debía hacer frente al pago de estas deudas tomando nuevos contratos. En mayo de 1575 , por todo ello, la situación era insostenible y se escribía que:

Estos intereses son muy excesivos y en grandíssimo daño de la hazienda de Su Magestad y son ynçufribles. Vuestra Excelencia los considere y que si se han

58 AGS, CMC, 1. ${ }^{2}$ época, leg. 1029: Relaçión de los cambios que quedan a pagar de los que se han tomado en esta ciudad de Barcelona por cuenta de Su Magestat (1567-12-31). 
de tomar para feria de Pasqua que serán los pagamientos a 8 de junio y para aqui vendrán a 8 de julio a pagar que se padecerán en dos meses a lo menos 5 por ciento que no se puede padeçer.

$Y$ estos cambios eran sólo una parte del total de 20.000 ducados (480.000 s.) que se debian haber conseguido de hombres de negocios catalanes el año anterior de 1574, para hacer frente a los gastos del ejército de las fronteras francesas. De esta cantidad sólo se logró contratar un total de $384.000 \mathrm{~s}$. y, la mayor parte, a los altisimos intereses que hemos apuntado 59 .

Finalmente, queda por hacer algún comentario sobre la cronología. Veremos que permite plantear unas hipótesis sobre la influencia de la coyuntura mercantil y los cambios en la subvención global de las finanzas imperiales. La serie que he estudiado abarca el periodo 1566-1587 con interrupciones producto, en principio, de la falta de datos completos para algunos años por no haberse localizado los legajos correspondientes. Respecto a la fecha inicial coincide casi con precisión con el tramo entre los años 1562 y 1575, cuando las ferias de pagos de Castilla ralentizaron su actividad y descoordinaron sus pagos ${ }^{60}$. Desde ese momento, las plazas bancarias de la Corona de Aragón se reactivaron en la búsqueda de integraciones a nivel del propio territorio y, sobre todo en el caso de Barcelona, de enlaces europeos. Los catalanes establecidos en Lyon ejercieron un papel acorde con su posición en la geografía del capital catalán de la época. Su capacidad financiera no era demasiado alta ni sobresaliente en el conjunto europeo, según los datos que proporciona R. Gascon, pero aquello que les confería gran trascendencia y ventajas eran las conexiones por toda Europa desde Lyon ciudad, que, en estos años, era el punto de «culminación de una amplia escala de actividades» ${ }^{61}$.

En este sentido los cambios en las ferias de pagos de Lyon, con más amplias posibilidades de especulación, abrieron la puerta al paulatino refinamiento de los intereses financieros. Aunque la decretal de 1571 de Pío V aclara el panorama de lo lícito y lo ilícito en los cambios ${ }^{62}$, esto no supuso - como recogía Vilar siguiendo las quejas elevadas desde la Lonja de Barcelona ${ }^{63}$ - el fraca-

59 AGS, Consejo y Juntas de Hacienda, leg. 146, carpeta 8: «Relaçión de los cambios que se an de pagar de León y del daño que ha havido en ellos a Su Magestad en esta feria passada de Reyes de León año 1575». Las dificultades por las que atravesaba durante ese mismo año la Real Hacienda redujeron el margen de maniobra de los oficiales reales y contribuirian a explicar los altísimos beneficios de los financieros barceloneses; Lovett (1980), pp. 909-911.

${ }_{60}$ Ruiz Martin (1992), pp. 187-188.

61 Braudel (1993), vol. I, p. 287.

62 Roover (1953), pp. 72-73.

63 Vilar (1968), pp. 280-282. 
so de Barcelona como plaza de cambios más que en los aspectos más honorables y legales de los mecanismos de legislación financiera. Los contratos simulados y los cambios secos prosiguieron, como lo prueban los protocolos notariales de la época o las cuentas de los pagadores.

Y la relación con Lyon se afianzó con mayor fundamento. Desde 1575, tras casi una década de «largas de ferias», los reinos de la Corona de Aragón comenzaron a girar aún más sus dineros sobre Lyon ${ }^{64}$. Un práctico del derecho público catalán, repasando el tema de la usura y recurriendo a los fondos de la Real Audiencia, resaltará cómo en los años 1578 y 1579 se procedió por este tribunal contra muchos comerciantes, «usurarios volente exigere credita secundum litteras cambii quas constabat esse simulatas» ${ }^{65}$. Son precisamente los años de gran actividad de los contratos de cambios.

Todo este entramado de relaciones se muestra influenciado por las vicisitudes de la coyuntura. Por ello, en 1591 se asiste a una crisis ante la que sólo cabe como solución un cambio de geografía del capital financiero y mercantil catalán, que se deja ya entrever durante estos años ${ }^{66}$. En mayo de 1591, según Rafael Balcells, importante mercader, no hay hombres de negocios en Lyon y el usado de las letras que vuelven a Barcelona - que solía ser de 60 a 70 diases ahora de 200 días. El número de letras libradas sobre la plaza francesa es bajísimo y se aproxima a la par la cotización del escudo de oro y la libra barcelonesa. La opción de tomar a Zaragoza desde Barcelona también presenta problemas de beneficios. De esta manera, aunque continúa la sociedad de los Granollachs en Lyon (ahora asociados a Melcior Boldo), se dan los primeros ensayos en busca de la alternativa. Desde Barcelona, Bernardí y Francesc Granollachs libran letras sobre las ferias de Besançon, lo mismo que Baltasar Pardina. Son intentos prematuros porque, como escribe Balcells, la contratación desde la capital catalana con Besançon es muy dificil. Así, en este imparable intento de conservar el necesario contacto europeo y, en cierto modo, la trama especulativa, se probará el envio de letras de Barcelona a Palermo. Allí los corresponsales catalanes menudean y son los que renegocian las letras hacia Lyon, que mantiene tantos lazos aún con el capital barcelonés ${ }^{67}$.

${ }^{64}$ Basas (1963), p. 210.

65 Peguera (1613), vol. I, p. 91.

66 Los detalles de la crisis de las sociedades catalanas en Lyon pueden verse en Hernández (1995), p. 267 y ss. La perspectiva crítica del sistema fiscal y financiero de la Monarquía durante estos años ha sido bien planteada por Grendi (1994), pp. 570-572.

67 Cf. las cartas del mercader Rafael Balcells, desde Barcelona, a Federico Hinderhofen en Zaragoza (1591-05-09, 1591-05-28 y 1591-10-11/16); a Juan Daniel Esleyquer en Zaragoza (1591 07-06) y a Climent Talavera en Palermo (1591-10-16). El proceso se irá generalizando; el dinero para Lyon se «retira» tanto que no se encuentran cambios para aquella ciudad en diciembre de 
Creo que debe relacionarse esta situación con la falta de datos sobre contratos de cambios con la Corona. En 1592, «la gent no està posada sinó en tenir la asienda prop que ningú la vol luniar dessí que assí no ' $s$ fa negosi nengú a causa de la temporada», se lamenta el mercader catalán cuando escribe a Roma. La «temporada» venía asociada con una reorientación de las rutas tradicionales y la consolidación del predominio de los intereses italianos que llevaria a la conversión de Cataluña en un hito en la ruta entre Castilla e Italia ${ }^{68}$.

De cualquier manera, también deben tenerse presentes las variaciones ocurridas en el suministro de fondos a la monarquia gracias al triunfo de los grandes contratos de asiento. En adelante, prevalece el sistema de grandes asientos concertados directamente con el Consejo de Hacienda por los banqueros italianos, que son los que luego reciben los pagos del cuantioso donativo de la corte de Barcelona de 1599 , sin dejar ya lugar - salvo en su participación como factores- a los activos mercaderes catalanes de las décadas anteriores ${ }^{69}$.

\section{CONCLUSIONES}

Podemos extraer algunas conclusiones finales. En lo que respecta a los hombres de negocios y su participación en el negocio de los cambios de Lyon: ¿esta inversión no comercial que realizan es inversión no productiva o especulativa? La respuesta está de acuerdo con los beneficios obtenidos en su relación general con las finanzas de la monarquía. Aunque los contratos estaban sometidos al albur de las variaciones de cotización en los cambios retornados desde Lyon, a la vista de los procesos estudiados parece claro que en general los finales siempre fueron positivos para los mercaderes particulares. Asimismo, la relación de dependencia que se estableció entre éstos y los oficiales de

1592, lo contrario que para Besançon (R. Balcells a J. D. Esleyquer, 1592-12-14); aunque en 1593 Balcells reconozca que únicamente hay dos o tres individuos que den letras para las ferias geno. vesas (R. Balcells a $F$. Hinderhofen, 1593-02-04/08). La correspondencia está conservada en ACA, AG, vol. 114.

${ }_{68} \mathrm{Ibidem}$. R. Balcells a Jeroni Verdú en Roma (Barcelona, 1592-07-15). Unos meses más tarde escribe a Esleyquer advirtiendole que "como solian enbiar a Lión aora enbían a Génova los más tenderos de acám (Barcelona, 1592-10-14). La coyuntura lyonesa de estos años explica el desarreglo de los cambios; Lapeyre (1955: 456-460). Los memoriales citados en la nota 72 de este trabajo, por otro lado, parecen refrendar la idea de una reorientación de los tratos financieros hacia las ferias genovesas en la última década del siglo Xvı.

69 Véase, p. e., AGS, DGT, inv. 24, leg. 273: «Duque de Maqueda, virrey de Cataluña. Cargo de los mrs. que se le entregan para cossas del serviçio de su Magd. desde el año de 1594 en adelante». La misma trayectoria de ignorancia del capital privado catalán en la financiación de la Corona se comprueba en ibidem, inv. 24, legs. 574 y 575 (pagador Diego de Vergara y Gaviria). 
la Real Hacienda, mediante la profusión de créditos contraídos por los agentes de la Corona a título particular, se vio reflejada en mercedes y privilegios: desde el encargo de la propia gestión patrimonial dejada en manos de los financieros catalanes a los titulos de nobleza concedidos. Son elementos de difícil valoración cuantitativa, pero de indiscutible validez cualitativa.

Resultó imposible, en determinados años, prescindir de los aportes de créditos privados. El recurso a la administración hacendística de la Diputación no era factible por impedimentos constitucionales del propio organismo autónomo; según el virrey Hernando de Toledo, en 1574 los diputados eran «implaticables» y no atendian a anticipar dinero o negociarlo a crédito ${ }^{70}$.

En cualquier caso, a esta capacidad de resultar imprescindibles financieramente a la monarquia y a los diversos medios de presión, los mercaderes catalanes unieron la ventaja de actuar en un territorio protegido por una legislación propia. De esta manera, pudieron hacer frente a cualquier amenaza. En ocasiones, ante el retraso o la negativa en la devolución de los créditos, algunos negociantes buscaron la intervención protectora de la Diputación. Es lo que hicieron Francesc Cassador y Damià Puiggener en 1576, cuando reclamaron al virrey deudas con intereses por más de 2.060 .000 sueldos, resultando con éxito su procedimiento. Igual acaeció en los sucesivos y siguientes altercados e intentos de extorsión por oficiales reales de los banqueros Cassador (1578), Rovirola (1584) o Puiggener (1589) ${ }^{71}$.

Por otro lado, respecto al ámbito financiero privado catalán, la importancia alcanzada por las conexiones europeas no decrecerá a fines del siglo XVI, aunque variarán las redes de extensión geográfica del mundo comercial. De esta manera, el tejido mercantil catalán había consolidado en las décadas finales del siglo xvi un ámbito propio de negociación que le permitió gozar de una amplia autonomía respecto a las variables de la economía peninsular y que prosiguió, peculiarmente, en las primeras décadas del siglo XVII. Siempre tuvieron un papel predominante los mecanismos financieros que vincularon a Cataluña con las plazas de cambio europeas. La imposibilidad de realizar compras directas fuera del Principado por la debilidad exterior de la moneda catalana muy devaluada condujo al planteamiento de una red financiero-mercantil muy compleja. Desde el Principado se enviaban paños de lana y otras mercancías (tejidos en general, vino, hierro) hacia Nápoles, Sicilia y otras regiones, principalmente italianas. Del valor obtenido con su venta se tomaban letras

70 AGS, GA leg. 78, f 43 y 320 (sobre el contexto de esta afirmación, en marzo de 1574).

71 Dietaris de la Generalitat de Catalunya, Barcelona, 1994-1996, vol. II (pp. 517, 533-534) y vol.

III (pp. 56-58, 256-257). ACA, G, vols. N.148 (f. 674-675v) y N.805 (f. 192v-194). 
de cambio - siguiendo, quizá, los procedimientos especulativos descritos - para las plazas de Novi o Plasencia «ahont y ha tan grans cantitats de diner, que de dites plaçes se fa provisió en Lió, y moltes parts de Alemània, y Flandes, per pagar les robes que de dits llochs vénen en aquest Principat». De esta manera, el trayecto ideal no contemplaba, en ningún tramo, la salida de numerario efectivo de Cataluña. El mercader que había realizado el envio hacia Italia podia cobrar y tomar nuevas letras simultáneamente sobre los «botiguers» y compradores catalanes del exterior. También sobre la misma estructura, las instituciones como la Diputación del General efectuaban pagos en Roma por razón de bulas, breves o beneficios eclesiásticos «que altrament serie necessari enviar lo diner effectivament, o ab lletres des de esta Provincia, a costa de molt grans interessos». La utilidad y ventajas que habian hecho prosperar esta red financiera y mercantil se mostraba, decían Narcís Peralta y Francesc Marti Viladamor, al constatar cómo en las galeras hacia Italia nunca se cargaba dinero de particulares sino mercancías para la venta en el mercado italiano ${ }^{72}$.

Persistían en las primeras décadas del siglo XviI, alterados en la geografía y la disposición monetaria, los instrumentos mercantiles puestos al servicio de la Corona en época de Felipe II. La variación simultánea en el sistema de asientos de financiación de la monarquia restó importancia a los créditos contratados en Barcelona a través de las ferias de pagos en Lyon, aunque operaciones de menor calado especulativo de sostenimiento de la Real Hacienda y sin relación con los cambios se mantendrían, al menos, hasta 1640.

72 Biblioteca Universitaria de Barcelona, ms. 1009 (Fr. Gaspar Vicens, O.P., «Miscelánea politico eclesiástica», vol. II), f. 357-357v. También es interesante el impreso «Lo remey que proposan los senyors consellers de Barcelona, per a remediar la necessitat que tenen en Catalunya de moneda de plata", conservado en el AHCB, Consell de Cent, XV-4, f. 291-299v. 
APÉNDICE

\begin{tabular}{|c|c|c|c|}
\hline Fecha & Valor (sueldos) & Dador del dinero a cambio & Plaza \\
\hline 1566-05.11. & $48.000,00$ & CODINA P.B. & Valencia \\
\hline 1566-05-13. & $48.000,00$ & GUIRZES G. & Valencia \\
\hline $1566-09-05 \ldots \ldots \ldots \ldots$ & $48.000,00$ & GUIRZES, G. & Valencia \\
\hline $1566-10-05 \ldots \ldots \ldots \ldots$ & $21.196,00$ & FERRERES P. & \\
\hline $1566-10-20 \ldots \ldots \ldots$ & $33.135,00$ & SAURI J. & \\
\hline $1566-11-09 \ldots \ldots \ldots \ldots$ & $17.296,00$ & CELLERS G. & Valencia \\
\hline 1566-11-16. & $9.600,00$ & ROS J. & Valencia \\
\hline 1566-11-19. & $14.400,00$ & ISERN A. & Valencia \\
\hline 1567-02-26. & $72.000,00$ & TAVERNER B. & Zaragoza \\
\hline $1567-04-29 \ldots \ldots$ & $36.000,00$ & SAURI J. & Valencia \\
\hline $1567-05-13 \ldots \ldots \ldots \ldots$ & $96.000,00$ & ROVIROLA J. & Valencia \\
\hline $1567-05-16 \ldots \ldots \ldots$ & $48.000,00$ & REGUER F. & Valencia \\
\hline 1567-06-04. & $8.000,00$ & REGUER F. & Valencia \\
\hline 1567-06-06 & $41.166,67$ & CREUS B. & Lyon \\
\hline $1567-06-09 \ldots$ & $24.000,00$ & NICOLAU P. & Medina \\
\hline $1567-07-01 \ldots \ldots \ldots \ldots$ & $24.000,00$ & MADUXER M. & Medina \\
\hline $1567-08-06 \ldots \ldots \ldots$ & $24.000,00$ & ROVIROLA J. & Medina \\
\hline $1567-10-10 \ldots \ldots \ldots \ldots$ & $180.000,00$ & FERRERES P. & Lyon \\
\hline $1567-10-20 \ldots \ldots \ldots \ldots$ & $200.000,00$ & REGUER F. & Lyon \\
\hline $1567-10-27 \ldots \ldots \ldots \ldots$ & $80.000,00$ & ROVIROLA J. & Lyon \\
\hline $1568-04-07 \ldots \ldots \ldots \ldots$ & $40.000,00$ & CASADEMUNT F. & Lyon \\
\hline 1568-04-07 .......... & $80.000,00$ & GENER J. J. & Lyon \\
\hline $1568-04-07 \ldots \ldots \ldots \ldots$ & $40.000,00$ & MADUXER M. & Lyon \\
\hline $1568-05-04 \ldots \ldots \ldots \ldots$ & $198.300,00$ & FERRERES P. & Lyon \\
\hline $1568-05-04 \ldots \ldots \ldots \ldots$ & $220.500,00$ & REGUER F. & Lyon \\
\hline 1568-05-04 ........... & $80.200,00$ & ROVIROLA J. & Lyon \\
\hline 1568-05-22. & $21.576,00$ & CALDARRIAGA P. & Zaragoza \\
\hline 1568-05-22. & $21.576,00$ & FERRERES P./CASSADOR F. & Valencia \\
\hline $1568-05.22 \ldots \ldots \ldots \ldots$ & $21.576,00$ & MADUXER M. & Valencia \\
\hline $1568-06-04 \ldots \ldots \ldots \ldots$ & $24.000,00$ & FERRER DESPUIG F. & Medina \\
\hline $1568-06-04 \ldots$ & $195.000,00$ & FERRERES P. & Lyon \\
\hline $1568-06-04 \ldots$ & $48.000,00$ & PUIGGENER D. & Medina \\
\hline $1568-10-17 \ldots \ldots \ldots \ldots$ & $44.526,50$ & CASADEMUNT F. & Lyon \\
\hline $1568-10-17 \ldots \ldots \ldots \ldots$ & $683.055,00$ & FERRERES P. & Lyon \\
\hline $1568-10-17 \ldots \ldots \ldots \ldots$ & $178.350,00$ & GENER J. J./ROVIROLA J. & Lyon \\
\hline $1568-10-17 \ldots \ldots \ldots \ldots$ & $44.741,50$ & MADUXER M. & Lyon \\
\hline $1569-01.20 \ldots \ldots \ldots$. & $431.000,00$ & FERRERES P./REGUER F. & Lyon \\
\hline $1569-01-20 \ldots \ldots \ldots$. & $160.000,00$ & GENER J. J./ROVIROLA J. & Lyon \\
\hline $1569-01-20 \ldots \ldots \ldots \ldots$ & $10.788,00$ & GUIRZES G. & Valencia \\
\hline 1569-01-20 .......... & $100.000,00$ & PUIGGENER F. & Lyon \\
\hline $1569-01-20 \ldots \ldots \ldots \ldots$ & $120.000,00$ & SOLS A. & Lyon \\
\hline $1569-01.20 \ldots \ldots \ldots \ldots$ & $160.000,00$ & TAVERNER B. & Lyon \\
\hline
\end{tabular}


APÉNDICE (Continuación)

\begin{tabular}{|c|c|c|c|}
\hline Fecha & Valor (sueldos) & Dador del dinero a cambio & Plaza \\
\hline $1569-01-26$ & $44.275,00$ & CASSADOR P. & Lyon \\
\hline $1569-01-26 \ldots \ldots \ldots \ldots$ & $44.275,00$ & MADUXER M. & Lyon \\
\hline $1569-01-26 \ldots \ldots \ldots \ldots$ & $45.400,00$ & ROVIROLA J. & Lyon \\
\hline $1569-05.28 \ldots \ldots \ldots \ldots$ & $4.050,00$ & MADUXER M. & Lyon \\
\hline $1569-05-28 \ldots \ldots \ldots \ldots$ & $12.150,00$ & ROS J. & Lyon \\
\hline $1569-07-06 \ldots \ldots \ldots \ldots$ & $1.088 .441,30$ & FERRERES P. & Medina \\
\hline $1569-07-15 \ldots \ldots \ldots$ & $106.200,00$ & PUIGGENER D. & Medina \\
\hline $1569-07-15 \ldots \ldots \ldots \ldots$ & $24.199,99$ & PUIGGENER F. & Lyon \\
\hline $1569-07-15 \ldots \ldots \ldots \ldots$ & $53.149,92$ & PUIGGENER P. & Medina \\
\hline $1569-07-15 \ldots \ldots \ldots \ldots$ & $51.889,00$ & SAURÍ J. & Medina \\
\hline $1581-03-13 \ldots \ldots \ldots \ldots$ & $40.000,00$ & PUIGGENER D. & Mallorca \\
\hline $1581-04-05 \ldots$ & $40.000,00$ & PUIGGENER D. & Mallorca \\
\hline $1581-07-17 \ldots$ & $120.466,66$ & PUIGGENER D. & Lyon \\
\hline $1581-12-19 \ldots$ & $550.000,00$ & PUIGGENER D. & Madrid \\
\hline $1582-09-12 \ldots$ & $70.000,00$ & REGUER F. & Lyon \\
\hline $1583-03-24 \ldots$ & $60.000,00$ & PUIGGENER D. & Lyon \\
\hline $1583-04-22 \ldots$ & $20.000,00$ & PUIGGENER D. & Lyon \\
\hline $1583-05-05$. & $34.000,00$ & SAURI J. & Madrid \\
\hline $1584-01-03$. & $72.003,86$ & PUIGGENER D. & Lyon \\
\hline $1584-01-14$. & $30.847,38$ & PUIGGENER D. & Lyon \\
\hline $1584-01-27 \ldots$ & $144.003,00$ & PUIGGENER D. & Lyon \\
\hline $1584-02-23 \ldots \ldots \ldots \ldots$ & $71.997,38$ & PUIGGENER D. & Lyon \\
\hline $1584-06-08 \ldots \ldots \ldots \ldots$ & $64.774,08$ & PUIGGENER D. & Lyon \\
\hline $1584-06-15 / 16 \ldots \ldots \ldots$ & $107.029,98$ & REGUER F. & Lyon \\
\hline $1584-06-26 \ldots \ldots \ldots \ldots$ & $34.673,33$ & BENET G./LAUDENS R. & Lyon \\
\hline 1584-09-04. & $48.000,00$ & PUIGGENER, D. & Madrid \\
\hline $1584-09-04 \ldots \ldots \ldots \ldots$ & $46.666,00$ & REGUER F. & Lyon \\
\hline $1584 \cdot 10-28 \ldots \ldots \ldots \ldots$ & $131.995,73$ & PUIGGENER D. & Lyon \\
\hline $1584-12-29 \ldots \ldots \ldots \ldots$ & $100.035,97$ & GRANOLLACHS B. y F. & Lyon \\
\hline 1585-01-19. & $29.527,19$ & GRANOLLACHS B./PARDINA B. & Lyon \\
\hline $1585-01-19 \ldots \ldots \ldots \ldots$ & $10.473,75$ & REGUER/GRANOLLACHS/PARDINA & Lyon \\
\hline $1585.02-07 \ldots \ldots \ldots \ldots$ & $47.500,00$ & PUIGGENER D. & Lyon \\
\hline $1585-02-18$. & $23.000,00$ & SANTCLIMENT J. & Lyon \\
\hline $1585-02-20 \ldots \ldots \ldots \ldots$ & $92.000,00$ & PUIGGENER D. & Lyon \\
\hline $1585-02-20 \ldots \ldots \ldots \ldots$ & $23.000,00$ & TAMARED F, J. & Lyon \\
\hline 1585-02-22. & $23.506,00$ & CASAMITJANA $\mathrm{M}$. & Lyon \\
\hline 1585-02-22. & $19.842,00$ & PUIGGENER D. & Lyon \\
\hline 1585-03-01. & $23.000,00$ & CASAMITJANA M. & Lyon \\
\hline $1587-05-14 \ldots \ldots \ldots \ldots$ & $40.000,00$ & LOMELIN B. & Madrid \\
\hline
\end{tabular}




\section{BIBLIOGRAFIA}

Adroer, Anna M.a y FeluU, Gaspar (1989): Història de la Taula de Canvi de Barcelona, Barcelona, Caixa de Barcelona.

BASAS, Manuel (1963): El consulado de Burgos en el siglo XVI, Madrid, CSIC.

Bernabé, David (1993): «La fiscalidad en los territorios peninsulares de la Corona de Aragón durante la época de los Austrias», en J. I. Fortea/C. M. ${ }^{a}$ Cremades (eds.), Politica y bacienda en el Antiguo Régimen, Murcia, Universidad de Murcia, vol. I, pp. 15-31.

Braudel, Fernand (1993): El Mediterráneo y el mundo mediterráneo en la época de Felipe II, Madrid, FCE, 2 vols.

Calabria, Antonio (1989): «Finanziari genovesi nel Regno di Napoli nel Cinquecento», Rivista Storica Italiana, vol. CI-III, pp. 578-613.

CONDE, Rafael (1990): «Las operaciones americanas de los Moradell», en XIII Congrés d'història de la Corona d'Aragó, Palma de Mallorca, 1990, vol. III, pp. 125-139.

(1993): «Tipologia de la documentació canviària medieval», Lligall, núm. 7, pp. 43-64

Dedieu, Jean-Pierre, y Ruiz, José Ignacio (1994): «Tres momentos en la historia de la Real Hacienda», Cuadernos de bistoria moderna, núm. 15, pp. 77-98.

ElLIoTT, John H. (1989): La revolta catalana 1598-1640. Un estudi sobre la decadencia dEspanya, Barcelona, Crítica.

FluviA, Armand de (1994): «Genealogia de la família Puiggener: de pagesos a Jorba a marquesos a Barcelona», en Miscel - lània en bonor del Doctor Casimir Martí, pp. 257. 263, Barcelona, R. Dalmau.

GASCON, Richard (1973): Grand commerce et vie urbaine au XVI siècle. Lyon et ses marchands (environs de 1520-environs de 1580), París, SEVPEN, 2 vols.

Gracia, Manuel (1986): «Aportación al estudio económico de la Gran Armada. Las libranzas del pagador Juan de Huerta en Lisboa», Revista de historia naval, núm. 13, pp. 51.78 .

GRENDI, Edoardo (1994): «Gli asientos dei Balbi e il Conte di Villalvilla», Rivista Storica Italiana, vol. CIV-III, pp. 565-621.

Hernández, Bernardo (1993): «La receptoria de la Bailía General de Cataluña durante el siglo xvim, Pedralbes, núm. 13-II, pp. 25-33.

- (1995): Aproximación a las estructuras fiscales de Cataluña en el siglo xvi. El Real Patrimonio y la Hacienda áe la Corona, 1516-1640, trabajo de doctorado, Universidad Autónoma de Barcelona.

- (1995b): «Barcelona i Catalunya dins la ruta imperial dels metalls preciosos. Les llicències de propi ús concedides per la Generalitat, 1559-1599», comunicación inédita al IV Congrés d'bistòria de Barcelona, Barcelona, diciembre de 1995.

HeRnandez EsteVE, Esteban (1992): Noticia del abastecimiento de carne en la ciudad de Burgos (1536-1537). Libro Mayor del obligado de las carnicerías, Madrid, Banco de España.

- (1988): «Comentario histórico-contable sobre los libros de cuentas de Diego Ordóñez (29 de noviembre a 18 de diciembre de 1518)», Revista española de financiación y contabilidad, núm. 55, pp. 223-276.

LAPEYRE, Henri (1955): Une famille de marchands: les Ruiz. Contribution à l'étude du commerce entre la France et lEspagne au temps de Philippe II, Paris, Armand Colin. 
LAPEYRE, Henri (1982): La Taula de Cambis (en la vida económica de Valencia a mediados del reinado de Felipe II), Valencia, Del Cenia al Segura.

(1978): «El mercado de cambios de Valencia en la época de Felipe Il», en A. Otazu (dir.), Dinero y crédito (siglo XVI al xIX), Madrid, Moneda y Crédito pp. 125-139, .

LOVETt, Albert W. (1980): «The Castilian bankruptcy of 1575», Historical Journal, vol. 23.4, pp. 899-911.

Noguera, Ramón (1950): «Protesto del siglo xv de una letra con la ricorsan, Estudios históricos y documentos de los archivos de protocolos, vol. II, pp. 325-327.

PEGUERA, Lluis de (1613): Decisiones aureae civiles et criminales in actu practico frequentissimae; ex variis Sacri Cathaloniae Senatus Conclusionibus, et responsis eorum..., Turín, 2 vols.

PENA, Manuel (1996): Cataluña en el Renacimiento: Libros y lenguas, Lleida, Milenio.

RIPOLL, Acaci de (1660): De magistratu Logiae Maris antiquitate, praebeminentia, iurisdictione, ceremoniis servandis, de causis modis eas tractandis, et decidendis..., Barcelona.

ROOVER, Raymond de (1953): L'évolution de la lettre de change. XIVe-XVIII siècles, París, Armand Colin.

Rurz MarTIN, Felipe (1965): Lettres marchandes échangées entre Florence et Medina del Campo, Paris, SEVPEN.

- (1975): «Joan y Pau Sauri: negociantes catalanes que intervienen en las empresas imperiales de Felipe II", en Homenaje al Doctor Don Juan Reglà Campistol, Universidad de Valencia, vol. I, pp. 457-474.

(1992): «La plaza de cambios de Valencia (siglos XIV-XviII)», en Economía española, cultura, sociedad. Homenaje a Juan Velarde Fuertes, Madrid vol. I, pp. 181- 210.

TORres, Xavier (1992): «Activitats econòmiques», en Historia de Barcelona, vol. 4, pp. 215-255, Barcelona, Enciclopedia Catalana-Ayuntamiento de Barcelona.

VÁzQUEZ DE PRADA, Valentín (1993): «La institución bancaria en Barcelona (siglos XV-XVII)», Pedralbes, núm. 13-I, pp. 495-504.

VILAR, Pierre (1968): Catalunya dins lEspanya moderna, Barcelona edicions 62, volumen 2. 